\title{
INFLAMMATORY RESOLUTION: NEW OPPORTUNITIES FOR DRUG DISCOVERY
}

\section{Derek W. Gilroy ${ }^{\star}$, Toby Lawrence ${ }^{\ddagger}$, Mauro Perretti ${ }^{\star}$ and Adriano G. Rossi ${ }^{\text {\} }$}

Treatment of inflammatory diseases today is largely based on interrupting the synthesis or action of mediators that drive the host's response to injury. Non-steroidal anti-inflammatories, steroids and antihistamines, for instance, were developed on this basis. Although such small-molecule inhibitors have provided the main treatment for inflammatory arthropathies and asthma, they are not without their shortcomings. This review offers an alternative approach to the development of novel therapeutics based on the endogenous mediators and mechanisms that switch off acute inflammation and bring about its resolution. It is thought that this strategy will open up new avenues for the future management of inflammation-based diseases.

We have come a long way in our understanding of inflammation since the days of Celsus (about $30 \mathrm{BC}$ to $38 \mathrm{AD}$ ) and his original description of the inflammatory response in terms of cardinal signs - heat, redness, swelling and pain. Dotted throughout its colourful history, inflammation research has had innumerable individuals who have described many of the mechanisms associated with tissue injury. Among these are Lewis (1881-1945), who described the Triple Response; Cohnheim and Samuel (late 1800s), who reported on leukocyte emigration and vascular permeability; and Metchnikoff (1845-1916), who described phagocytosis, to name but a few ${ }^{1}$. However, even until the midtwentieth century our understanding of the chemical mediators that bring about these events - in particular, changes that lead to VASCULAR LEAKAGE, pain and cell accumulation - was lacking. Indeed, Wilhelm, writing in the mid-1960s, commented that "Half a century of work on the identification of substances increasing vascular permeability and the other vascular events in the inflammatory process has resulted in little reliable information concerning relevant chemical mediators"'. The subsequent 40 years of research have made up for this shortfall by revealing many of the factors that we now know propagate the initial response to tissue injury (BOX 1). However, once the inflammatory leukocyte and the exudate have entered the inflammatory site and neutralized the inciting agent, they must be eliminated and cleared in a NON-PHLOGISTIC manner. This is acute inflammatory resolution, a burgeoning area of inflammation research that might help to understand the aetiology of chronic inflammation. Like Wilhelm and colleagues in the 1960s, who lamented the lack of understanding of the mediators that drive acute inflammation, we stand now in the new millennium knowing little of what switches it off. In much the same way as pharmacologists developed drugs based on blocking what initiates and drives inflammation, perhaps now we can develop new anti-inflammatory drugs based on mimicking those molecules that resolve the problem.

\section{What is inflammatory resolution?}

It is a popular misconception that once the inflammatory response has neutralized an injurious stimulus, inflammation somehow fizzles out, possibly from proinflammatory mediator catabolism. On the contrary, the resolution of acute inflammation is a highly coordinated and active process that is controlled by endogenous 'pro-resolving' mediators. These factors switch off leukocyte trafficking to the inflamed site, reverse vasodilation and vascular permeability, and bring 


\section{Box 1 | Mediators of the acute inflammatory response}

Mediators known to drive the acute inflammatory response

- The clotting system products (plasmin, fibrinopeptides)

- Fibrinolytic system products (fibrin)

- Kinins (bradykinin)

- Vasoactive amines (histamine and 5-hydroxytryptamine)

- Substance P

- Complement system by-products

- Eicosanoids (prostaglandins, leukotrienes and platelet activation factor)

- Cell-adhesion molecules

- Cytokines

- Chemokines

- Oxygen-derived free radicals

- Nitric oxide

Mediators recently found to be involved in pro-resolution

- Cyclopentenone prostaglandins

- Lipoxins/resolvins

- NF-кB (p50/p50)

- Mediators of apoptosis (caspases, CD44, etc.)

-Annexin-1 of an immune response to an endogenous antigen (autoimmunity) ${ }^{4-7}$. This review will not consider aspects of wound healing or chronic inflammation but will focus on the mediators and mechanisms that regulate the fate of inflammatory leukocytes during the resolution of acute inflammation.

\section{Why develop drugs based on resolution?}

A range of therapies exist for the treatment of inflammation-driven diseases such as asthma, rheumatoid arthritis, psoriatic arthritis, systemic lupus erythematosus, Crohn's disease, multiple sclerosis and systemic vasculitis. However, such therapeutics have undesirable side effects. For instance, steroids can cause osteoporosis ${ }^{8}$ and impair wound healing ${ }^{9}$, whereas novel selective inducible cyclooxygenase (COX) 2 inhibitors might reduce protective vascular prostacyclin synthesis, leading to an increased risk of thrombosis ${ }^{10}$. Indeed, experience with tumour necrosis factor- $\alpha$ (TNF- $\alpha$ )-neutralizing therapy has also revealed several complications ${ }^{11}$. Clinical studies indicate that TNF- $\alpha$-neutralizing therapy should not be given to patients with cardiac failure or a history of demyelinating disease. In addition, increased infection rates can occur, especially the activation of latent tuberculosis, although other opportunistic infections such as listeriosis, pneumonia and aspergillosis have also been reported. These unwanted side effects stem from the inhibition of essential endogenous factors that have a role in normal physiology or, in the case of anti-TNF- $\alpha$, by dampening down the host's ability to adequately deal with infection, given that the innate inflammatory response is a beneficial defensive event. Our view is that detailed characterization of the biochemical pathways leading to resolution might lead to the identification of novel targets that can be exploited for innovative antiinflammatory drug discovery. We foresee that novel compounds based on the mechanism of action of a given pro-resolving mediator will be modulatory in their action and likely to produce a lower burden of side effects.

\section{Mediators and mechanisms of resolution}

Studies on the resolution of acute inflammation have already revealed novel mediators with potent antiinflammatory properties. Determining their basic structure and function might help in the development of unique anti-inflammatory therapeutics. So far, these pro-resolving mediators have been shown to exert powerful anti-inflammatory effects in various experimental models of inflammatory diseases. Of these, lipid-mediator derivatives of the COX2 and lipoxygenase (LOX)/LOX interaction pathways of arachidonic acid, eicosapentaenoic acid (EPA) and docosahexaenoic acid (DHA) metabolism, as well as inducible haem-oxygenase (HO-1), will be described in this review. We will also discuss the fate of inflammatory leukocytes after their job is done (apoptosis), reveal a virtuous side to nuclear factor (NF)-кB and discuss how old workhorses of inflammation (glucocorticoids and annexins) cross paths with the new (lipoxins). 

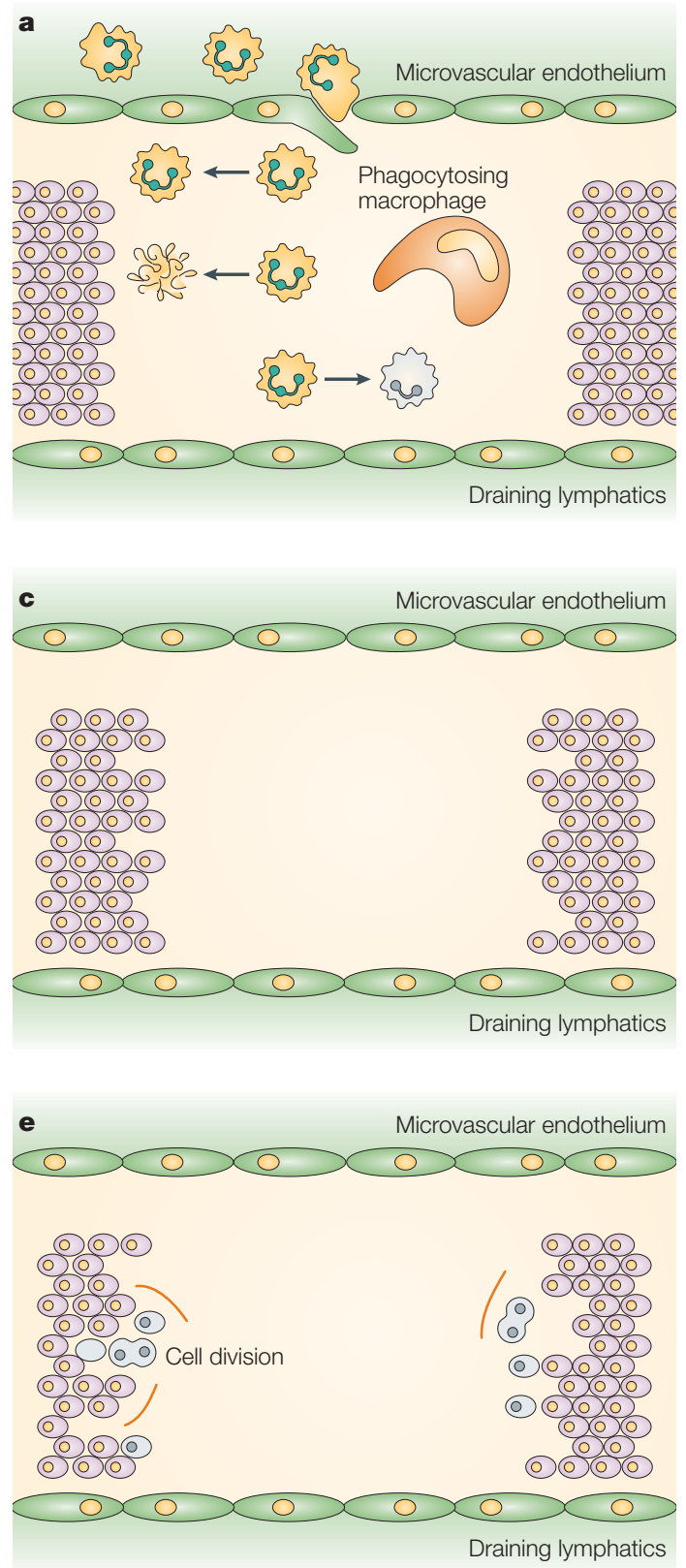

Figure 1 | Scheme of events depicting the various consequences to acute inflammation. In the first instance, inflammatory leukocytes migrate to the inflamed site or area of tissue damage, with PMNs or eosinophils being the first cell types at the scene (a). Although in some circumstances PMNs are cleared from the inflamed site by returning to the circulation, the most common fate of PMNs is apoptosis, after which they are phagocytosed by newly migrated macrophages (macrophages containing effete leukocytes are called Reiter cells). Macrophages, in turn, might apoptose locally or be cleared by lymphatic drainage (b), thereby allowing this acute inflammatory response to resolve and the inflamed tissue to return to its normal physiological function (c). Invariably, however, there is some evidence of parenchymal tissue damage (d), with some cells dying by necrosis but, in turn, being replaced by local tissue regeneration and some evidence of residual tissue scarring (e). If, however, the surrounding tissue damage is extensive, the process of healing is by repair. This involves the in-growth from the surrounding connective tissue of an initially vascular tissue containing endothelial cells, fibroblasts, myofibroblasts and macrophages, and is known as granulation tissue (f). After some time, the number of macrophages and myofibroblasts decline. Eventually, fibroblasts lay down collagen and the capillaries disappear, leaving a dense avascular, hypocellular extracellular matrix (g).
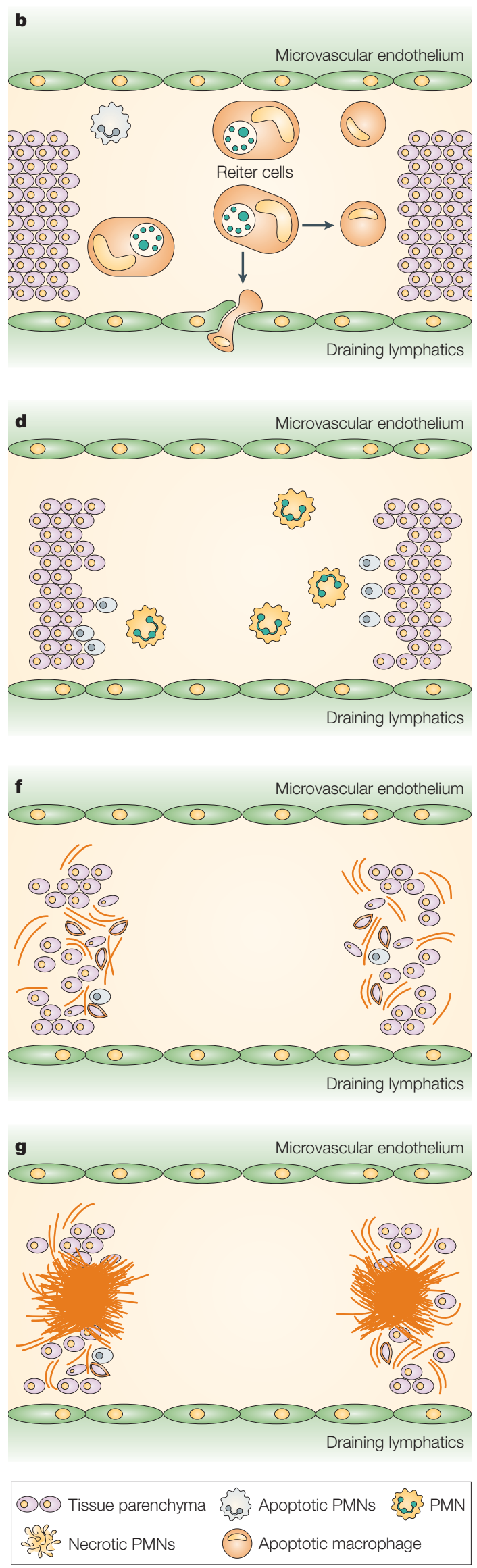
PEROXISOME PROLIFERATORACTIVATED RECEPTORS (PPARs). Members of the nuclear receptor family that regulate the transcription of genes involved in lipid and lipoprotein metabolism, glucose and energy homeostasis, as well as cellular differentiation. They consist of three isotypes: alpha (NR1C1), gamma (NR1C3) and beta/delta (NRC1C2), with a differential tissue distribution.

SIGNAL TRANSDUCERS AND ACTIVATORS OF TRANSCRIPTION Signal transducers and activators of transcription (STAT) proteins are intracellular effector molecules of cytokinemodulated signalling.

POLYMORPHONUCLEAR LEUKOCYTES

(PMNs). Discovered by Paul Ehrlich who used contemporary fixing and staining techniques to identify the lobulated nucleus and the granules that typify cells that we now classify as eosinophils, basophils and neutrophils. In the context of this review, PMNs refer to neutrophils.

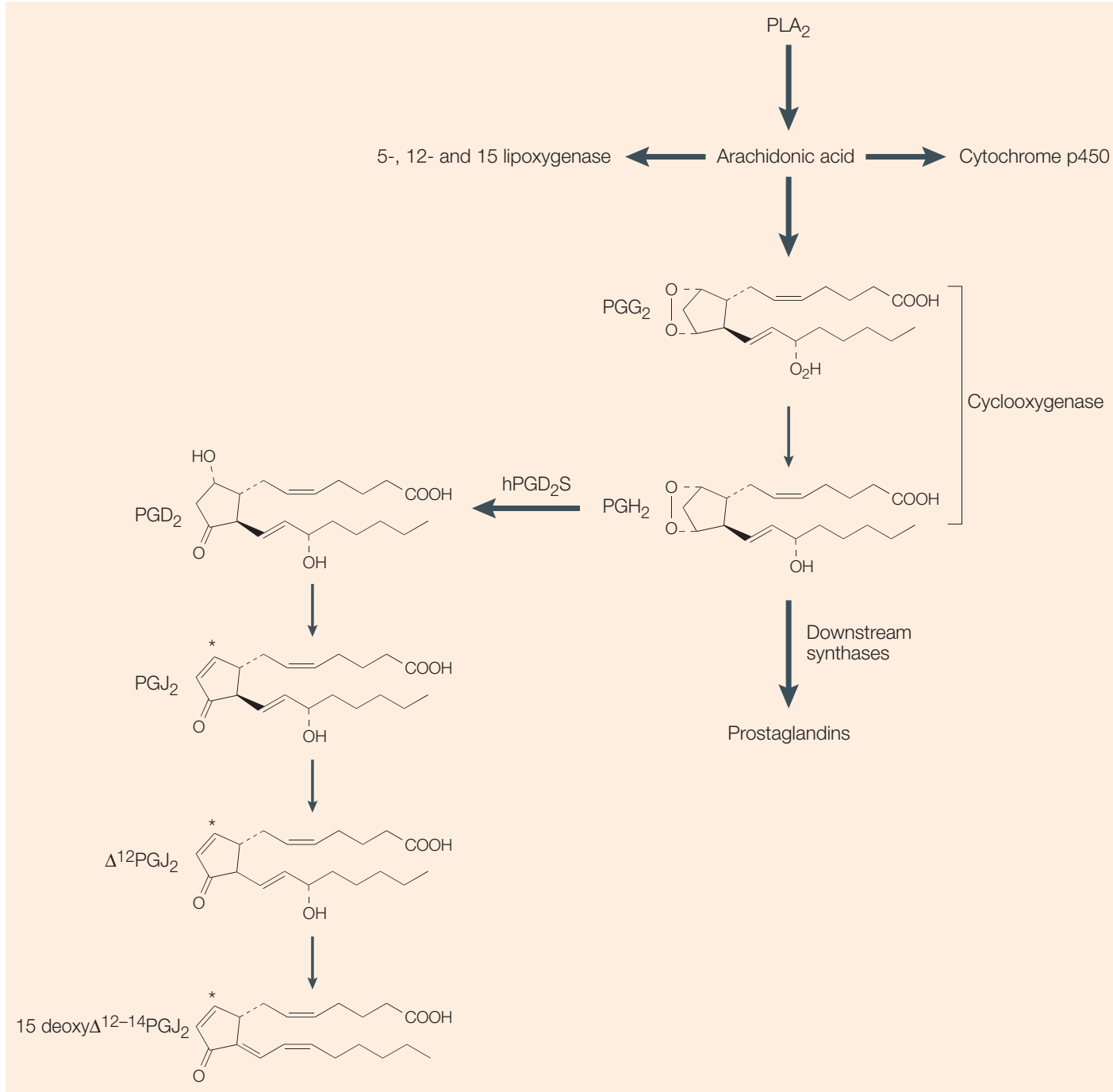

Figure 2 | Arachidonic metabolism by COX, as well as the LOX and cytochrome p450 family of enzymes. Arachidonic acid is released by either cytosolic, secretory or calcium-independent phospholipase $A_{2}$. The phospholipase $A_{2}$ involved is cell-type- and stimulus-specific. Liberated arachidonic acid is metabolized by cyclooxygenase (COX)1 or COX2 to $P G G_{2}$ and then $P G H_{2}$. $P G H_{2}$ serves as a substrate for a series of downstream synthases to give rise to the prostaglandins. For $P D_{2}$ synthesis, $P G H_{2}$ is metabolized by haematopoietic prostaglandin $\mathrm{D}_{2}$ synthase. $P G D_{2}$, in turn, is non-enzymically broken down to the cyPGs. $P G D_{2}$, prostaglandin $\mathrm{D}_{2} ; \mathrm{PGG}_{2}$, prostaglandin $\mathrm{G}_{2} ; \mathrm{PGH}_{2}$, prostaglandin $\mathrm{H}_{2}$.

\section{COX2-derived cyclopentenone prostaglandins}

Prostaglandin (PG) $\mathrm{D}_{2}$ is a major product from a COXcatalysed reaction in a variety of tissues and cells, including those of the immune system, such as mast cells, platelets, T cells, dendritic cells and macrophages. $\mathrm{PGD}_{2}$ has significant effects on a number of biological processes, including inhibition of platelet aggregation, vascular and nonvascular smooth-muscle relaxation, as well as sleep-wake regulation and inflammation ${ }^{12}$. PGD $_{2}$ undergoes dehydration in vivo and in vitro to yield biologically active $\mathrm{PGs}$ of the $\mathrm{J}_{2}$ series, including $\mathrm{PGJ}{ }_{2}$, $\Delta^{12,14}-\mathrm{PGJ}{ }_{2}$ and 15 -deoxy- $\Delta^{12,14}-\mathrm{PGJ}{ }_{2}\left(15 \mathrm{~d}-\mathrm{PGJ}{ }_{2}\right)^{2}$, which are characterized by the presence of a reactive $\alpha, \beta$-unsaturated ketone in the cyclopentenone ring ${ }^{13}$ (FIG. 2). Although 15d-PG) was initially identified as a high-affinity natural ligand for PEROXISOME PROLIFERATORACTIVATED RECEPTOR gamma $(\operatorname{PPAR} \gamma)^{14,15}$, it is now thought to exert its effects through PPAR $\gamma$-dependent as well as -independent mechanisms ${ }^{16}$, resulting in the suppression of various pro-inflammatory signalling pathways. These include pathways that operate through NF-кB, AP1 and SIGNAL TRANSDUCERS AND ACTIVATORS OF TRANSCRIPTION (STATs) $)^{14,15,17-19}$, as well as the suppression of inducible nitric oxide synthase, interleukin (IL) $-1 \beta$, TNF- $\alpha$ and IL-12 in macrophages ${ }^{14,20}$, microglial cells $s^{21,22}$ and dendritic cells $s^{23}$. 15d-PGJ ${ }_{2}$ also preferentially inhibits monocyte rather than POLYMORPHONUCLEAR LEUKOCYTE (PMN) trafficking through the differential regulation of celladhesion molecule and chemokine expression ${ }^{24-27}$, indicating that cyclopentenone PGs (cyPGs) do not control the onset phase of acute inflammation, in which PMNs predominate, but tightly regulate the chronicity of the inflammatory response. In support of this, we have shown that COX2 has a dual role in acute pleuritis ${ }^{28,29}$. 


\section{Box 2 | Cytokines and the resolution of acute inflammation}

In unpublished experiments, we found a peak in interleukin (IL)-10 and transforming growth factor (TGF)- $\beta 1$ expression during the resolving phase of acute inflammation, indicating an important role for these cytokines in pro-resolution. We suspect that they are synthesized by macrophages following the recognition of apoptotic

polymorphonuclear leukocytes (PMNs; see the in vitro work in REFS 81,138,140). In addition, is was recently reported that under the control of interferon (IFN)- $\gamma$, IL- 6 and its soluble receptor controls PMN trafficking in peritoneal inflammation by suppressing CXC and CC chemokine expression and hence further PMN recruitment ${ }^{146,147}$.

Furthermore, IL-6 and its soluble receptor promotes PMN apoptosis and clearance. This highlights some of the early signals that might influence the longevity of PMNs in self-limiting inflammation.

\section{DELAYED-TYPE}

HYPERSENSITIVITY

(DTH). A delayed-type

hypersensitivity or type IV

hypersensitivity is mediated by

$\mathrm{T}$ lymphocytes and not by

antibody-antigen complexes

(arthus or type III

hypersensitivity). Typically, this response occurs $24-72$ hours

after the sensitized host is

exposed to the offending

antigen. For example, a DTH

reaction might be set up

experimentally by sensitizing to methylated bovine serum

albumin in Freund's complete adjuvant and challenging 12

days later with the same antigen.

$\mathrm{T}_{\mathrm{H}} 1$

The $T_{H} 1 / T_{H} 2$ hypothesis came to prominence in the late $1980 \mathrm{~s}$, indicating that mouse T-helper $\left(\mathrm{T}_{\mathrm{H}}\right)$ cells broadly express differing cytokine profiles. Whereas T-helper $1\left(\mathrm{~T}_{\mathrm{H}} 1\right)$ cells secrete IFN- $\gamma$ and TNF- $\alpha$; $T_{H} 2$ cells secrete IL-4, IL- 5 and IL- 13 . In addition, $\mathrm{T}_{\mathrm{H}} 3$ and regulatory $\mathrm{CD} 25^{+} \mathrm{CD} 4{ }^{+} \mathrm{T}$ cells exist that produce TGF- $\beta$ and IL-10, respectively.

BILIVERDIN and BILIRUBIN Haem catabolites with antiinflammatory properties due to scavenging of free radicals.
This enzyme not only contributes to the onset of the reaction through the synthesis of pro-inflammatory $\mathrm{PGE}_{2}$, but also to its resolution through the preferential synthesis of $\mathrm{PGD}_{2}$ and $15 \mathrm{~d}-\mathrm{PG} \mathrm{J}_{2}$. Moreover, we recently identified the phospholipases (PLAs) that release arachidonic acid for these dual phases of eicosanoid metabolism with calcium-independent PLA, and to a lesser extent secretory $\mathrm{PLA}_{2}$, which is necessary for the onset phase switching to a requirement for cytosolic $\mathrm{PLA}_{2}$ coupling to COX2 during resolution for the generation of pro-resolving $\mathrm{PGD}_{2}$ (REF. 30). It seems that $\mathrm{PGD}_{2}$ and 15d-PGJ bring about resolution, in part, by inducing PMN and, surprisingly, macrophage apoptosis ${ }^{31}$, albeit a contentious issue. Indeed, of all the leukocytes, macrophages tend to be very resistant to undergoing programmed cell death. Yet, $15 \mathrm{~d}-\mathrm{PGJ}_{2}$ has previously been reported to induce granulocyte ${ }^{32}$, macrophage $e^{33}$ and, more recently, myofibroblast apoptosis ${ }^{34}$. These studies indicate that the cyPGs might not only be important for controlling the fate of inflammatory leukocytes during the resolution of acute inflammation, but also in preventing complications arising from excessive tissue fibrosis and wound healing.

That $15 \mathrm{~d}-\mathrm{PGJ}_{2}$ has both PPAR $\gamma$-dependent and -independent effects and that it is formed by nonenzymic dehydration from the parent eicosanoid, $\mathrm{PGD}$, makes tying down the precise contribution of $15 \mathrm{~d}-\mathrm{PGJ}{ }_{2}$ to the inflammatory response problematic. However, we can begin to get some idea about this by examining the inflammatory response in mice that are deficient in haematopoietic $\mathrm{PGD}_{2}$ synthase, the enzyme that synthesises $\mathrm{PGD}_{2}$ from its COX-derived $\mathrm{PGH}_{2}$ precursor. Therefore, in an immune-mediated DELAYED-TYPE HYPERSENSITIVITY reaction, mice that are deficient in haematopoietic $\mathrm{PGD}_{2}$ synthase showed an exaggerated inflammatory response that failed to resolve readily. Lymphocytes from these animals proliferated uncontrollably, producing a $\mathrm{T}_{\mathrm{H}} 1$-type cytokine profile and showed enhanced binding or pro-inflammatory NF- $\mathrm{B}$ activity (D.W.G., J. Newson, S. Gor and P.R. ColvilleNash, manuscript in preparation; see BOX 2). Despite the questions surrounding the PPAR $\gamma$-dependent or independent effects of $15 \mathrm{~d}-\mathrm{PG} \mathrm{J}_{2}$, these results are in general agreement with those obtained from PPAR $\gamma^{+/}$ mice with a type IV hypersensitivity reaction ${ }^{36}$. Similarly, when fibroblasts expressing retrovirally transfected haematopoietic $\mathrm{PGD}$, synthase complementary DNA
(cDNA) are introduced to mice bearing bleomycininduced lung injury, significantly reduced lung oedema, leukocyte infiltration in bronchoalveolar lavage fluid and pulmonary collagen content is observed, in addition to prolonging the lifespan of the transfected mice ${ }^{37}$. These results, as well as those showing a protective role for $15 \mathrm{~d}-\mathrm{PGJ}_{2}$ in models of ischaemia reperfusion injury $^{38,39}$, inflammatory bowel disease ${ }^{38}$, adjuvantinduced arthritis ${ }^{40}$ and experimental autoimmune encephalomyelitis $^{41}$, provide support for $15 \mathrm{~d}-\mathrm{PGJ}_{2}$ as a novel therapeutic agent against inflammatory diseases. $\mathrm{PGD}_{2}$ and the cyPGs might contribute to the resolution of inflammation through various mechanisms that include the inhibition of the expression of proinflammatory genes, the induction of apoptosis in activated macrophages and myofibroblasts, and the activation of PPAR $\gamma$. However, stable therapeutics based on $\mathrm{PGD}_{2}$ and its metabolites might not be a panacea for all inflammatory processes. For instance, in the lung there is mounting evidence that $\mathrm{PGD}_{2}$ might contribute significantly to the symptoms and pathogenesis associated with asthma ${ }^{42,43}$, indicating that although such putative endogenous PGs might be protective at one site of tissue injury, it might be detrimental at another, reflecting differing organ-specific aetiologies of disease processes in terms of onset and resolution.

\section{Effect of haem oxygenase induction}

There is still much debate over the differential effects of $15 \mathrm{~d}-\mathrm{PGJ}_{2}$ on pro-inflammatory cytokine synthesis. However, a closer look at the literature reveals that this disparity arises from the concentrations of $15 \mathrm{~d}_{-} \mathrm{PGJ} \mathrm{J}_{2}$ (ng or $\mu \mathrm{g}$ ) used on different cell types (peripheral blood monocytes-macrophages, J774 macrophages or A549 cells) that are stimulated differently (such as LPS, PMA and TNF- $\alpha)^{14,26,44}$. However, one interesting observation from these studies was the delayed but sustained inhibition of LPS-stimulated TNF- $\alpha$ release achieved by low concentration $15 \mathrm{~d}-\mathrm{PGJ} \mathrm{J}_{2}(0.5 \mu \mathrm{M})$ on LPS-treated $\mathrm{J} 774$ macrophages, which was attributed to the induction of HO-1 by 15 d-PGJ ${ }_{2}$ (REF. 44). HO- 1 is a stress-inducible enzyme that catalyses the degradation of haem to liberate free iron, carbon monoxide, BILIVERDIN and BILIRUBIN in mammalian cells ${ }^{45}$ and was one of the original endogenous factors identified as playing a crucial role in the resolution of acute pleuritis ${ }^{46}$, with current studies indicating that HO-1 might also have a role during the onset phase of acute inflammation by regulating PMN trafficking ${ }^{47}$. 15d-PGJ ${ }_{2}$ induction of HO-1 and its associated suppression of pro-inflammatory gene expression is certainly consistent with its role in acute inflammatory resolution, but the interaction between HO- 1 and $15 \mathrm{~d}_{-} \mathrm{PG}_{2}$ during this phase has yet to be clarified. Numerous studies have since reported an important role for HO-1 as a defence mechanism against oxidative insults through the antioxidant properties of biliverdin and bilirubin, as well as the anti-inflammatory action of carbon monoxide ${ }^{48}$. Moreover, in mouse-to-rat transplantation, induction of HO-1 by cobra venom factor and cyclosporine A in endothelial and smoothmuscle cells of cardiac xenografts prior to transplantation 
a

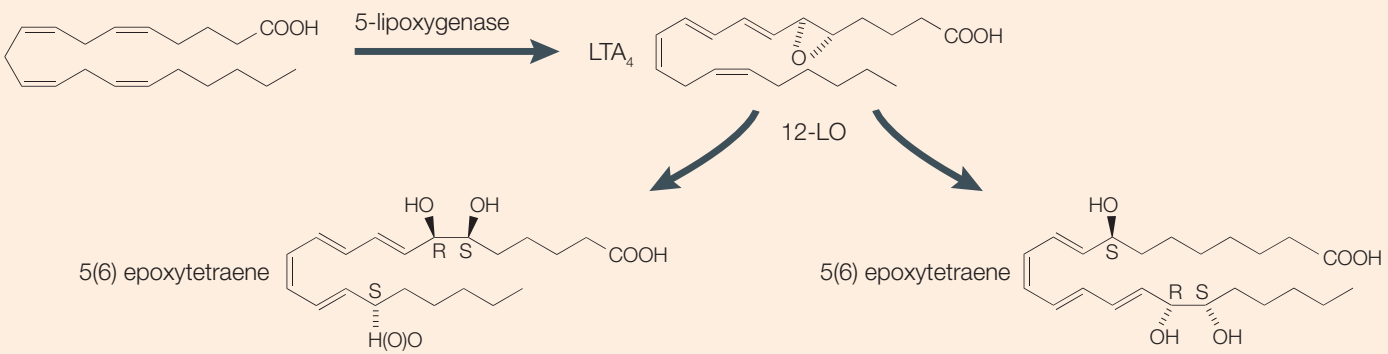

Lipoxin A4

Lipoxin B4

b
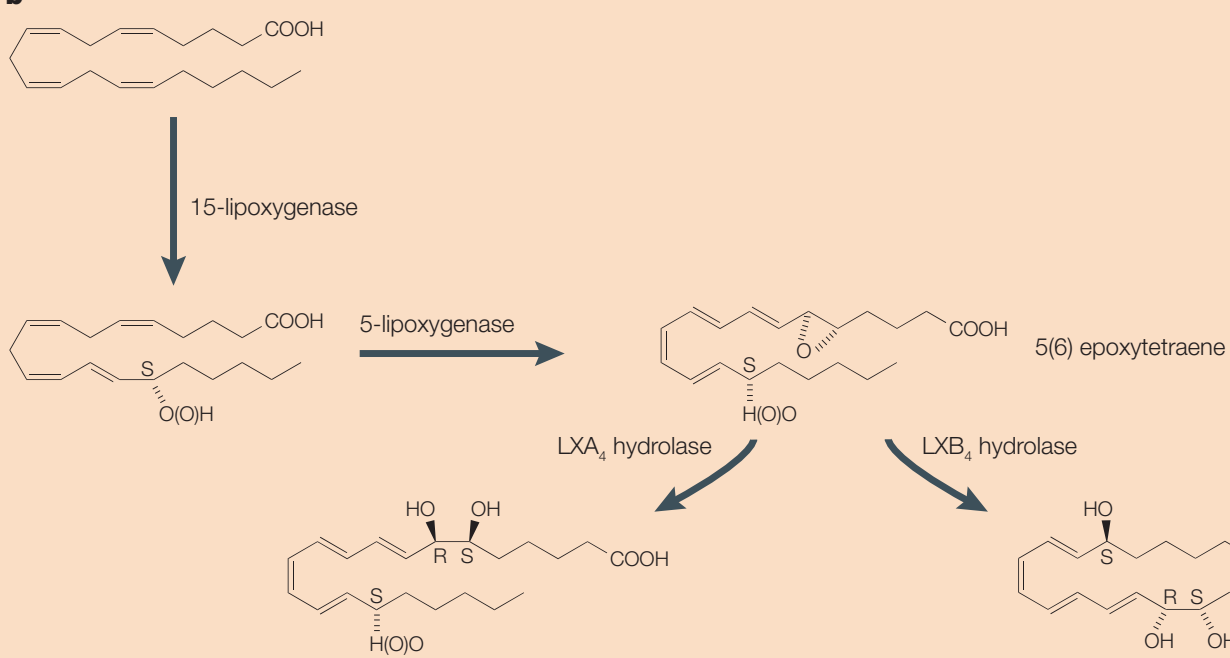

Lipoxin A4
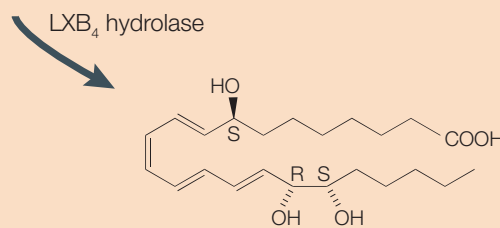

Lipoxin B4

c

Arachidonic acid

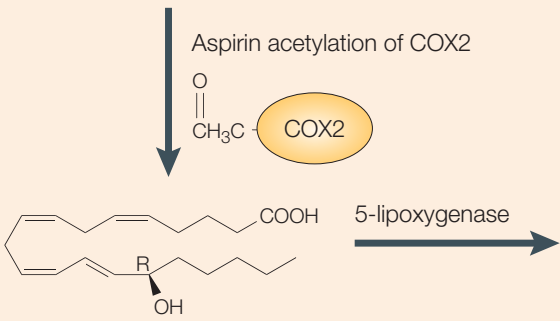

15R-HETE

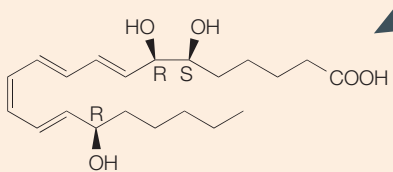

15-epi-lipoxin A4
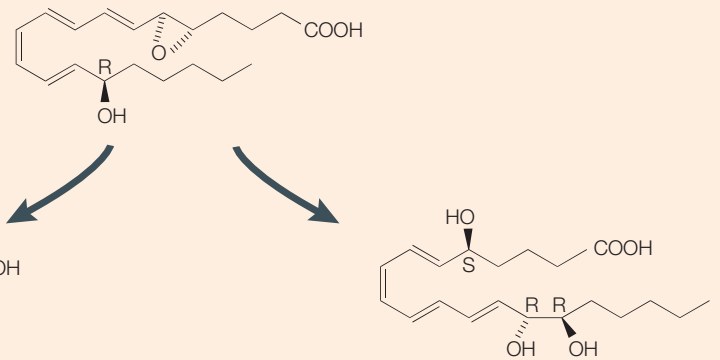

15-epi-lipoxin B4

Figure 3 | Biosynthesis of LXs occurs through three distinct biosynthetic pathways. a | The first is via platelet-PMN (polymorphonuclear leukocyte) interactions, whereby 5-LOX (lipoxygenase) in PMNs metabolizes arachidonic acid to leukotriene

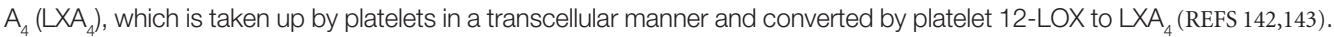
b | The second route of lipoxin $(L X)$ formation is via the action of monocytes or epithelial-cell 15-LOX. Molecular oxygen is inserted into carbon 15 of arachidonic acid, yielding 15(S)hydroperoxyeicosatetraenoic acid, which can then serve as a substrate for PMN 5-LOX to generate 5,6-epoxytetraene. This unstable epoxide intermediate is converted to LXA $A_{4}$ and $L X B_{4}$ by epoxide hydrolases in leukocytes ${ }^{144}$. A final and unorthodox route for LX metabolism involves aspirin ${ }^{145}$. c $\mid$ Aspirin acetylates the active site of cyclooxygenase (COX)2, resulting not in the inhibition of COX2 enzyme activity but in the conversion of arachidonic acid to 15(R)-hydroxyeicosatetraenoic, which when released from endothelial and epithelial cells might be transformed by leukocyte 5-LOX to generate 15-epi-LXA $\mathrm{A}_{4}$ or 15-epi-LXB . 
prolongs the survival rate of these organs ${ }^{49}$. Upregulation of HO-1 with anti-CD40L monoclonal antibody also protects mouse allografts against transplant rejection ${ }^{50}$, whereas induction of HO-1 by cobalt-protoporphyrin IX protects against murine acute graft-versus-host disease $^{51}$. So, compounds that regulate HO-1 might represent yet another strategy for the treatment of inflammatory diseases.

\section{The lipoxins and resolvins}

Lipoxins. Transcellular metabolism of arachidonic acid by LOX/LOX interaction pathways gives rise to the lipoxin (LX) family of eicosanoid metabolites (FIG. 3). LXs display selective actions on leukocytes that include inhibition of PMN chemotaxis ${ }^{52}$, PMN adhesion to and transmigration through endothelial cells $s^{53}$, as well as PMN-mediated increases in vascular permeability ${ }^{54}$. In contrast to their effects on PMN and eosinophils, LXs are potent stimuli for peripheral blood monocytes, stimulating monocyte chemotaxis and adherence ${ }^{55,56}$ without causing degranulation or release of reactive oxygen species $^{57}$. In fact, LXs and their stable analogues accelerate the resolution of allergic pleural oedema ${ }^{58}$ and enhance phagocytosis of apoptotic PMNs by monocyte-derived macrophages in a non-phlogistic fashion ${ }^{59,60}$, paving the way for a return to tissue normality. $\mathrm{LXA}_{4}$ and aspirintriggered 15-epi-LXA , as well as their stable analogues, act with high affinity at a $\mathrm{G}$-protein-coupled receptor, $\mathrm{LXA}_{4}$ receptor (ALXR; also referred to as formyl peptide receptor-like 1 or FPRL1). FPRL1 is a member of the family of seven transmembrane G-coupled receptors, which has at least two other members - FPRL2 and the formyl-Met-Leu-Phe receptor (FPR). By contrast, $\mathrm{LXB}_{4}$ does not bind the ALXR and, although functional studies have indicated the existence of a receptor that is activated by $\mathrm{LXB}_{4}$, this receptor has not been cloned ${ }^{61}$. As with the cyPGs, the LXs have also been identified as being expressed during and being crucially important for the resolution of acute inflammation. In a model of rat allergic oedema, for instance, $\mathrm{LXA}_{4}$ was identified along with $\mathrm{PGE}_{2}$ as being present during the clearance of oedema in this model ${ }^{62}$. Inhibition of their synthesis prolonged oedema clearance, which was rescued using stable analogues of these eicosanoids. A recent analysis of eicosanoid synthesis in a murine dorsal AIR-POUCH MODEL of acute inflammation elicited by TNF- $\alpha$ has revealed a switch in lipid-class metabolism reminiscent of that found in the rat carrageenin-induced pleurisy. In response to TNF- $\alpha$, levels of leukotriene $\mathrm{B}_{4}$ increased rapidly, followed by $\mathrm{PMN}$ infiltration, which coincided with a rise in inflammatory exudate PGE $_{2}$ (REF. 52). Concomitant with the eventual reduction in PMN numbers and $\mathrm{PGE}_{2}$ was an increase in $\mathrm{LXA}_{4}$. It was concluded that $\mathrm{PGE}_{2}$ induced a switch in lipid mediator synthesis from predominantly 5-LOX-generated leukotriene $\mathrm{B}_{4}$ to 15-LOX-elicited pro-resolving $\mathrm{LXA}_{4}$. Along with our findings in the rat carrageenin-induced pleurisy in terms of PG metabolism ${ }^{29,30}$, this work indicates that, in acute inflammation, lipid-mediator biosynthesis is biphasic, with a role for eicosanoids in the initiation as well as termination of the inflammatory response.
Resolvins. Arachidonic acid is not the only fatty-acid substrate that can be transformed by COXs and LOXs to bioactive mediators with roles in anti-inflammation and resolution. DHA and EPA — omega-3 fatty-acid constituents of fish oils - were shown recently to be metabolized during the resolving phase of an aspirintreated TNF- $\alpha$-induced inflammation to potent antiinflammatory products, aptly named resolvins ${ }^{63,64}$ (FIG. 4). For instance, endothelial cells expressing COX2 and treated with aspirin convert EPA to $18 R$-hydroxyeicosapentaenoic acid (HEPE) and 15R-HEPE. Both are subsequently used by PMNs to generate separate classes of novel trihydroxy-containing mediators that potently inhibit human PMN transendothelial migration ${ }^{63}$. Similarly, aspirin-acetylated COX2 converts DHA to 17R-HDHA, which is subsequently transformed by PMNs into two sets of novel di- and trihydroxy products that can inhibit microglial-cell cytokine expression and ameliorate experimental models of dermal inflammation and leukocyte accumulation in peritonitis at nanogram doses $^{64}$. Even in the absence of aspirin, human whole blood converts DHA to $17 \mathrm{~S}$ series resolvins as well as novel dihydroxy-containing docosanoids. DHA-loaded glial cells stimulated with zymosan also release docosanoids, with these novel resolvins possessing such potent anti-inflammatory effects as inhibiting leukocyte trafficking in vivo and pro-inflammatory cytokine release by stimulated human glial cells ${ }^{65}$.

Collectively, the LXs and resolvins represent novel classes of anti-inflammatory agents that are tightly associated with the resolution of acute inflammation and shown to be implicated in the pathogenesis of disease processes, including atherosclerosis ${ }^{66}$, periodontitis ${ }^{67}$, chronic liver disease ${ }^{68}$ and asthma ${ }^{69}$. Moreover, LXs and their analogues are proving to be highly effective therapeutics in a range of experimental disease models, including immune-mediated glomerulonephritis ${ }^{70}$ and renal ischaemia-reperfusion injury ${ }^{71}$, a range of skin inflammatory-like diseases ${ }^{72}$ and gastritis ${ }^{73}$. Lipid mediators of this sort are not only natural and essential components of acute inflammatory resolution, but show that when applied to inflammatory disease processes are highly effective, thereby providing the rationale for the development of compliant and stable mimetics that target key aspects of chronic inflammation, either ongoing or recurrent, forcing them down a revolving pathway and into remission.

\section{Apoptosis and phagocytosis}

What is the fate of inflammatory leukocytes after they have carried out their role? There are a number of routes available for the efficient clearance of these cells, including systemic re-circulation ${ }^{74,75}$, lymphatic drainage $^{76,77}$, or death by either apoptosis or necrosis followed by phagocytosis, with apoptosis followed by phagocytosis being considered the most desirable for successful resolution ${ }^{78}$. It is clear that apoptosis has a fundamental role in almost all biological processes and there is increasing evidence to indicate that dysregulated apoptosis is likely to be an important factor in the pathogenesis and progression of a number of diseases ${ }^{79,80}$. 


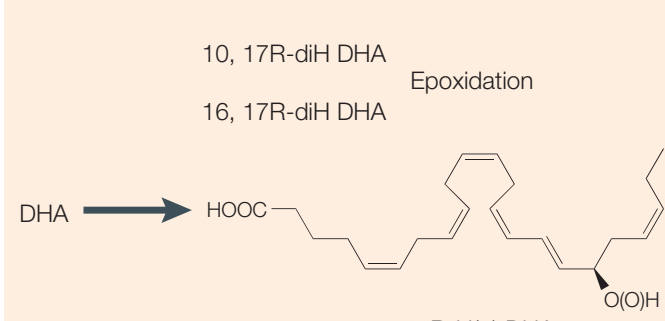

17R-H(p) DHA

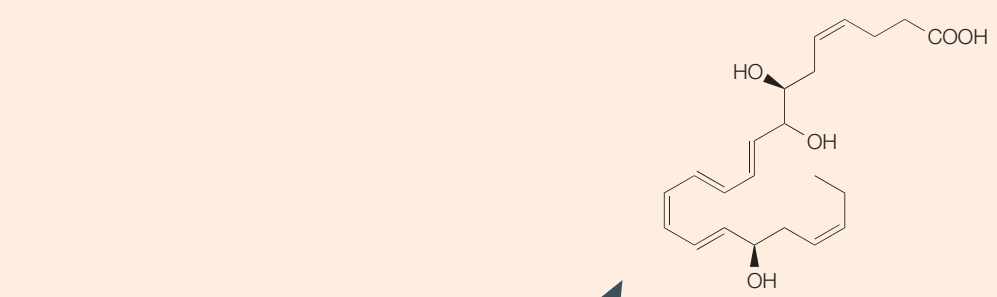

7S, 8, 17R-triHDHA

Resolvin D1

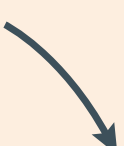

7(8)-epoxy-17R-DHA

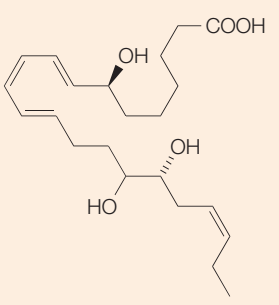

7S, 16, 17R-triHDHA Resolvin D2

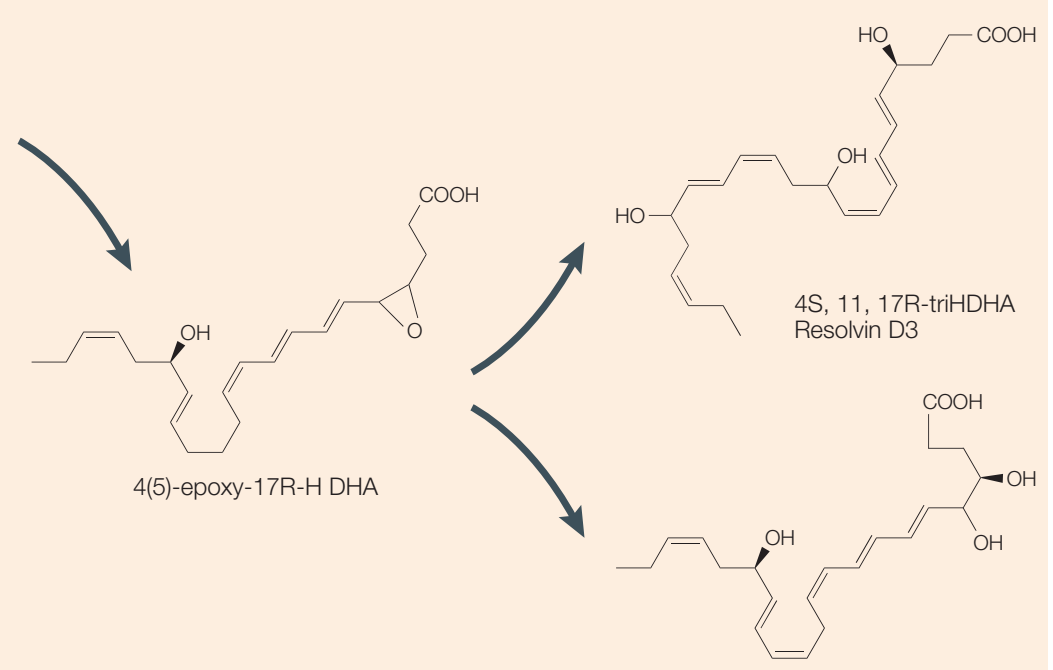

4S, 5, 17R-triHDHA Resolvin D4

\section{b 18R: E-series resolvins Aspirin: COX2}

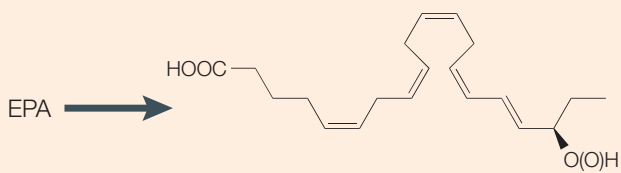

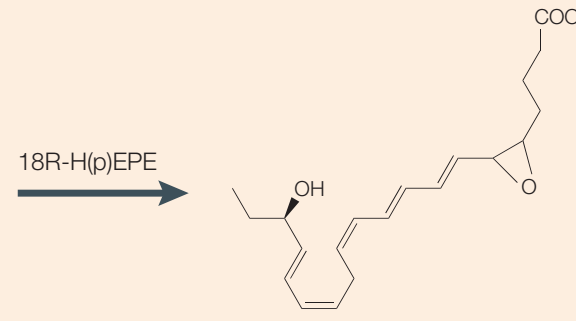

5s, 6R-epoxy, 18R-hydroxy-EPE
$\mathrm{COOH}$

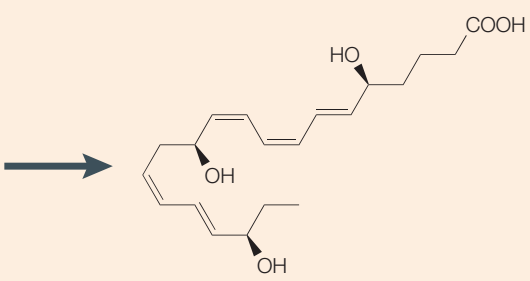

5S, 12R, 18R-trihydroxy-EPE Resolvin E1

Figure 4 | Synthesis of DHA- and EPA-derived eicosanoid resolvins. Arachidonic acid is metabolized by the aspirin-acetylated cyclooxygenase (COX)2/lipoxygenase (LOX) interaction pathway to the epi-LXs, and substitution of arachidonic acid with $\omega$-3 polyunsaturated fatty acids (such as DHA (docosahexaenoic acid) and EPA (eicosapentaenoic acid)) as substrates gives rise to the resolvins. a | Human COX2 can convert DHA to 13-hydroxy-DHA, which switches with aspirin to 17R-HDHA. Human PMNs transformed aspirinacetylated COX2-derived 17R-hydroxy-DHA into two sets of novel di- and trihydroxy products; one initiated via oxygenation at carbon 7 and the other at carbon 4 (REF. 64). b|By contrast, endothelial cells that express COX2 and that are treated with aspirin will convert EPA to 18R-hydroxyeicosapentaenoic acid and 15R-hydroxyeicosapentaenoic acid. Each can be further metabolized by PMNs to generate separate classes of novel trihydroxy-containing mediators, including 5-series 15R-LX $\mathrm{S}_{5}$ and 5,12,18R-trihydroxyeicosapentaenoic acid ${ }^{63}$. 
Enhanced undesirable apoptosis occurs in many neurological diseases, such as Alzheimer's disease, Parkinson's disease, Huntington's disease and multiple sclerosis. Furthermore, inappropriate inflammatory responses or dysfunctional vascular effects leading to tissue damage with increased apoptosis have been observed. So, there is good evidence of cell or tissue apoptosis during myocardial infarction, stroke or sepsis. Consequently, a therapeutic strategy to delay or inhibit apoptosis would seem a viable option assuming that cell specificity can be achieved.

On the other hand, there is much evidence indicating that reduced apoptosis occurs in most cancers. Essentially, as well as uncontrolled cell division or proliferation, there is an apparent failure of cancerous cells to undergo apoptosis. It has also been proposed that in many inflammatory diseases (for example, rheumatoid arthritis, atopic dermatitis, Crohn's disease, asthma and chronic obstructive pulmonary disease) there might be delayed apoptosis of key inflammatory cells, thereby prolonging the functional responsiveness of these potential histotoxic cells. A strategy to specifically promote death of cancer cells or tissue-damaging inflammatory cells is therefore likely to be therapeutically beneficial. However, any attempts to induce cell, especially inflammatory-cell, apoptosis must be matched by effective non-inflammatory clearance by phagocytic cells (for example, macrophages) ${ }^{60,78,81}$. Failure to remove these apoptotic cells would undoubtedly lead to the cells becoming necrotic, thereby increasing the potential for tissue damage occurring. Great progress has been achieved in recent years in the elucidation of the complex mechanisms that are involved in recognition of apoptotic cells (or apoptotic bodies) by phagocytes (at least 10 recognition mechanisms have been identified so far $)^{82}$. Furthermore, phagocytosis of apoptotic cells has been shown to be a highly regulatable process and therefore likely to be amenable to pharmacological manipulation $^{83,84}$. It has been shown, for example, that elevation of cAMP by $\mathrm{PGs}^{85}$ can downregulate macrophage capacity to ingest apoptotic cells, whereas treatment of phagocytes with glucocorticoids ${ }^{86,87}$, LXs $^{59}$ or even certain cytokines ${ }^{88}$ can markedly increase macrophage clearance of apoptotic cells. Interestingly, the environment in which phagocytes are likely to reside can also upregulate apoptotic-cell clearance. For example, interactions with extracellular-matrix components such as fibronectin ${ }^{89}$, and ligation of macrophage CD44 with crosslinking antibodies ${ }^{90}$, can augment the capacity of phagocytes to engulf apoptotic cells. So, clearance of apoptotic cells in a noninflammatory manner by phagocytes is a therapeutic possibility. Indeed, there is already evidence in animal models that CD44 has an important role in resolving lung inflammation ${ }^{91}$ and that glucocorticoids might exert some of their therapeutic beneficial anti-inflammatory effects in patients with asthma by influencing apoptosis and apoptotic-cell clearance ${ }^{92}$. Some of these novel developments have led to the design of drugs that have even gone into clinical trials ${ }^{79,93}$.
One extremely active area of drug development that targets apoptosis is the identification of small-molecule caspase inhibitors. Caspases are a family of cysteinyl aspartate-specific proteases that are of fundamental importance in the initiation and execution of apoptosis, ultimately being responsible for the dismantling of the cell during apoptosis ${ }^{94,95}$. A number of small-molecule inhibitors of caspases (for example, ZVAD-fmk) have already been tested in animal models of human disease with remarkable success. For example, specific caspase inhibitors have been shown to be effective in preventing or reducing the effects of ischaemia (for example, organ failure and death) in various animal models ${ }^{79,96,97}$. These inhibitors of apoptosis are now being tested pre-clinically or have reached clinical trials for hepatic disease, acute myocardial infarction and sepsis ${ }^{93}$. A good example of a novel specific broad-spectrum caspase inhibitor that has been successfully used pre-clinically is IDN-6556 (REF. 98). This compound, administered by a number of routes, was shown to be potent and efficient in reducing signs of liver damage in in vivo rodent models of liver disease. It was shown that the compound seemed to exert its activity by effectively inhibiting caspase activity $^{99}$. Furthermore, this drug has successfully undergone Phase II clinical trials for liver disease in which it was well tolerated and reduced plasma alanine aminotransferease activity, a marker for hepatic injury, in patients with liver impairment ${ }^{100}$. There are a number of other drugs that are in development for inhibiting apoptosis, but so far the most promising therapeutic development is in the induction of apoptosis, especially for the treatment of a number of cancers. The strategy for inducing apoptosis has been to block powerful survival pathways by, for example, inhibiting BCL2-mediated survival using antisense oligonucleotides, and interference of survival pathways that are mediated by NF- $\mathrm{B}$, phosphoinositol-3-kinase and tyrosine kinase activation. Another strategy is to directly induce apoptosis by engaging death-receptor pathways (such as FASR, TNFR and TRAILR) or by other less welldefined mechanisms ${ }^{93}$.

\section{NF-KB}

The NF- $\kappa B$ pathway is pivotal in the inflammatory response by regulating the expression of pro-inflammatory cytokines, chemokines and inducible enzymes ${ }^{101}$. Furthermore, NF- $\kappa \mathrm{B}$ controls the expression of antiapoptotic genes that might protect inflammatory leukocytes from programmed cell death ${ }^{102}$, an important determinant of inflammatory resolution. Given the central role of this pathway in the initiation of the inflammatory response and preservation of leukocyte longevity, it seems that factors that threaten the pro-inflammatory or anti-apoptotic status of NF- $\kappa \mathrm{B}$ would hasten the resolution of inflammation. Some insight into this was provided by the PPAR $\gamma$-independent inhibitory effects of $15 \mathrm{~d}-\mathrm{PGJ}_{2}$ on NF- $\kappa \mathrm{B}$ activation (see BOX 3 ). For example, the NF- $\kappa \mathrm{B}$ pathway regulates the expression of the anti-apoptotic protein BCL-X $\mathrm{X}_{\mathrm{L}}$, the promoter activation of which is inhibited by $15 \mathrm{~d}-\mathrm{PGJ}{ }_{2}$. This leads to programmed cell death of CD28 co-stimulated 
a

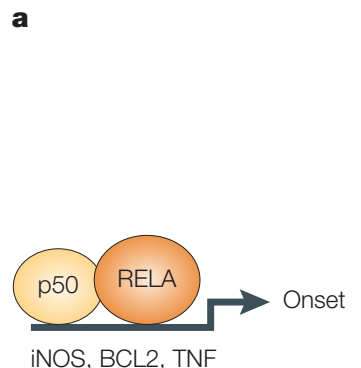

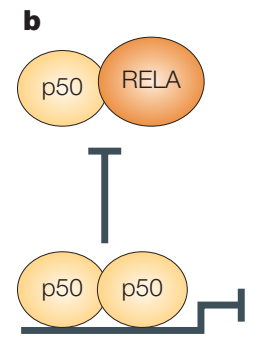

iNOS, BCL2, TNF c

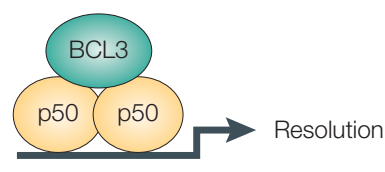

COX2, BAX, p53

Figure 5 | The profile of NF-KB subunit binding from onset to resolution in acute inflammation. a | Inhibition of nuclear factor of $\kappa B(N F-\kappa B)$ at the onset of the inflammatory response resulted in the inhibition of acute inflammation due to the binding of the proinflammatory NF-KB subunits p50/RELA. b | At resolution, however, there was predominance of p50-p50 homodimers, which is responsible for pro-inflammatory mediator suppression and the induction of pro-apoptotic gene expression leading to the onset of resolution (c). The inhibition of $\mathrm{NF}-\kappa \mathrm{B}$ during this phase prevented resolution.

complexes such as p50-p50 homodimers, which might antagonize NF- $\kappa \mathrm{B}$-dependent pro-inflammatory gene expression while simultaneously promoting the expression of genes that are required for the resolution of inflammation. Broad-spectrum inhibitors of the NF- $\kappa \mathrm{B}$ pathway, such as antioxidants and proteasome inhibitors, had the expected anti-inflammatory actions during the initiation of inflammation. However, when administered after the onset of inflammation, these inhibitors prevented resolution, which was associated with the inhibition of leukocyte apoptosis. We hypothesize that this alternative NF- $\kappa \mathrm{B}$ pathway promotes leukocyte apoptosis through the recruitment of NF- $\mathrm{KB}$ DNA-binding complexes that lack transactivation domains and act as dominant-negative inhibitors of anti-apoptotic gene expression (see FIG. 5). Indeed, the persistence of p50-p50 homodimers during the resolution of inflammation is perhaps not surprising considering the reported role of p50-p50 in the repression of pro-inflammatory gene transcription ${ }^{106,107}$. Transgenic mice that express $\mathrm{p} 50$ but not the inhibitory carboxyl terminus of the p105 molecule showed increased p50-p50 DNA-binding activity ${ }^{106}$. These mice show reduced expression of cytokine genes in resident macrophages and impaired leukocyte recruitment, indicating p50-mediated suppression of inflammation in vivo. These studies also revealed that in certain cell types p50-p50 might enhance gene transcription, particularly when complexed with the IкB-like protein BCL3. This might help explain the unlikely expression of COX2 during resolution as RELA-p50 and p50-p50 complexes bind to distinct $\kappa \mathrm{B}$ response elements in the COX2 promoter, whereas the p50-p50 complex alone can also upregulate COX2 transcription through association with transcriptional co-activators of the C/EBP family.

These studies might also help explain, at the molecular level, how NF- $\kappa$ B controls leukocyte clearance during resolution. We found that inhibition of p105 processing to 50 and of NF- $\mathrm{KB}$ DNA-binding activity by the proteosome inhibitor MG132 reduced the This involves the recruitment of alternative DNA-binding

\section{Box 3 | PPAR $\gamma$-independent inhibitory effects of $15 d-P G \mathbf{J}_{2}$ on $\mathbf{N F}-\kappa \mathbf{B}$ activation}

Although 15d-PGJ ${ }_{2}$ exerts some of its anti-inflammatory effects through peroxisome proliferator-activated receptor gamma (PPAR $\gamma$ ) activation, resulting in, for example, the inhibition of nuclear factor of $\kappa B(N F-\kappa B) D N A$ binding ${ }^{15}$, it seems that $15 \mathrm{~d}-\mathrm{PGJ}{ }_{2}$ has more of an effect on the inflammatory response by altering the activation of NF- $\mathrm{KB}$ directly. Through Michael addition reactions, the highly reactive electrophilic carbon atom in the unsaturated carbonyl group of the cyclopentane ring can react with nucleophiles, such as the free sulphydryl groups of glutathione (GSH) and cysteine residues that form disulphide bonds in proteins ${ }^{17,148}$. In this respect, cyclopentenone PGs (cyPGs) can modify conserved cysteine residues located in both the trans-acting DNA-binding proteins of NF- $\mathrm{KB}$ and elements of the upstream

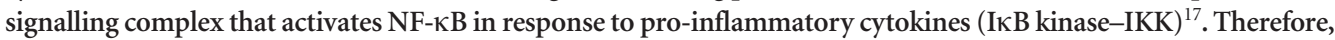
$15 \mathrm{~d}-\mathrm{PGJ}{ }_{2}$ can alkylate Cys179 of IKK $\beta$, which is located in the kinase activation loop ${ }^{149}$. The DNA-binding subunits of NF-kB, p50 and RELA might also be alkylated at Cys62 and Cys38, respectively, by 15dPGJ (REF. 150). These residues are located in the DNA-binding domains of the proteins and their alkylation prevents the activation of gene expression representing multiple targets for the inactivation of NF- $\mathrm{KB}$ by $15 \mathrm{~d}-\mathrm{PGJ}{ }_{2}$. It was shown recently that $15 \mathrm{~d}-\mathrm{PGJ} \mathrm{J}_{2}$ was not detectable during adipocyte differentiation, throughout the time course of LPS-administration to humans or in the synovial fluid of arthritic patients, questioning the status of $15 \mathrm{~d}-\mathrm{PGJ}_{2}$ as an endogenous PPAR $\gamma$ receptor ligand ${ }^{151}$. However, given its short half-life and propensity to bind avidly to sulphydryl groups, one possible reason why $15 \mathrm{~d}_{-} \mathrm{PG} \mathrm{F}_{2}$ is not readily detectable in biological fluids is because it is bound to pro-inflammatory signalling proteins. Perhaps a more appropriate strategy is to look for intracellular 15d-PGJ ${ }_{2} /$ protein complexes. 
expression of the pro-apoptotic proteins BAX and p53 in leukocytes during the resolution of acute inflammation ${ }^{105}$. Finding BAX and p53 expressed during resolution in this model is highly significant in itself as it identifies the signalling pathways that mediate leukocyte apoptosis during acute resolution in vivo. Although the BAX promoter contains both $\kappa \mathrm{B}$ and $\mathrm{p} 53$ response elements, BAX is thought to be a target gene for $\mathrm{p} 53$ rather than NF- $\kappa$ B. As $\mathrm{p} 50-\mathrm{p} 50$ homodimers are known to positively regulate the $\mathrm{p} 53$ promoter, it is interesting to speculate that p53 and NF- $\mathrm{KB}$ (p50-p50) cooperate to regulate BAX expression and leucocyte apoptosis during resolution, which would certainly explain why p53 and BAX expression is diminished after NF- $\kappa B$ inhibition during this period. Signal-induced processing of p105 to p50 is dependent on inducible phosphorylation and proteosome-mediated limited proteolysis, which is dependent in turn on the IKK complex. However, although the IKK complex is essential for inducible p105 processing, IKK $\beta$ is redundant in this pathway. It could be hypothesized that endogenous anti-inflammatory mediators such as cyPGs repress the activation of IKK $\beta$, leading to a predominance of anti-inflammatory signalling pathways that are regulated independently of IKK or by an alternative IKK complex that mediates $\mathrm{p} 105$ processing. It should be noted that recent data with tissue-specific knockout experiments of IKK $\beta$ have illustrated the possible adverse side effects of global IKK $\beta$ inhibition ${ }^{108}$. It was shown that inhibition of IKK $\beta$ expression in colonic epithelial cells increases apoptosis in response to ischaemia reperfusion injury, leading to a loss of barrier function and considerable intestinal damage. This indicates a tissue-specific role for IKK $\beta$ in inflammation: IKK $\beta$ inhibition might reduce pro-inflammatory cytokine production and leukocyte recruitment, and inhibition of anti-apoptotic pathways might result in increased tissue injury. This might be particularly important in epithelial cells at mucosal surfaces that have a barrier function, such as the lung and the intestine. Understanding of these molecular mechanisms that terminate pro-inflammatory signalling pathways and promote the resolution of inflammation will enable the design and development of more specific and appropriate pharmacological agents with therapeutic potential for the treatment of chronic inflammatory diseases.

\section{Glucocorticoids and annexin}

Glucocorticoids are endogenous potent anti-inflammatory mediators that are released within minutes in response to stress and tissue injury to control the severity of the inflammatory response, functioning as internal brakes against potentially exaggerated inflammatory reactions mounted by the host ${ }^{109}$. Accordingly, removal of this potent and primary braking mechanism is associated with augmented and prolonged inflammation, including, in some cases, lethality ${ }^{110,111}$. Although probably not released into the circulation during the resolution of acute inflammation, glucocorticoids might act, in part, by speeding up resolution in certain disease processes. For instance, glucocorticoids selectively induce eosinophil apoptosis and, like the LXs, also enhance macrophage phagocytosis of apoptotic bodies. This indicates that the role of steroids in the treatment of chronic inflammation, such as asthma, might be to reprogramme this ongoing inflammatory lesion down a pro-resolution pathway.

It is now clear that the unbound glucocorticoid receptor $(\mathrm{GR})$ is associated within the cytoplasm in a non-active oligomeric complex with regulatory proteins such as heat-shock proteins 90 and 70, p59 immuno-philin and p23 phosphoprotein ${ }^{112}$. Receptor engagement leads to GR activation, which occurs in at least two distinct ways. Following ligand binding, the GR undergoes a conformational change leading to dissociation from specific proteins and the formation of glucocorticoid/GR complex monomers or dimers. In the latter case, the complex translocates into the nucleus to control gene transcription. Monomer glucocorticoid/GR, however, might also regulate several specific biochemical pathways, including the RELA subunit of NF- $\mathrm{KB}$ and the JUN and FOS components of AP1 (REFS 101,113-115) — so-called 'non-genomic' effects of glucocorticoids. This is an area of active research for the identification of glucocorticoids with distinct genomic versus non-genomic properties. No studies have yet addressed the question of whether these non-genomic actions of glucocorticoids can 'modulate' specific signal-transduction pathways that favour resolution.

As well as binding to cytoplasmic steroid hormone receptors, glucocorticoids also modulate the expression and secretion of regulatory proteins that have antiinflammatory actions, of which the peptide annexin-1 (lipocortin-1) has been well described in vitro and in vivo ${ }^{116-119}$. Of a protein more than 300 amino-acids long, small peptides drawn for the amino-terminal region of annexin-1 retain biological activity. As the annexin-1 amino terminus is not homologous to other members of the family, it is likely that these peptides reflect solely the biological effects of annexin-1 (REFS 41,120,121). The availability of a biologically active peptide sequence could certainly be the starting point for the development of new anti-inflammatory entities. However, as small molecules are certainly more appealing for drug discovery, identification of the precise target for anti-inflammatory actions of annexin- 1 has long been required. Recent data showed an unexpected twist in this area, showing that annexin-1 and LXA share the same ALX receptor ${ }^{122}$. Human recombinant annexin-1 and annexin-1-derived peptides competed with $\mathrm{LXA}_{4}$ for receptor binding not only on engineered cells but also on human PMNs. These results, and the fact that the ALXR binds other endogenous proteins ${ }^{123}$ (including serum amyloid protein A), broadens our understanding of the endogenous control of acute inflammation by suggesting that this anti-inflammatory receptor has been evolutionarily kept for multi-use, that the ALXR is pivotal for controlling the inflammatory response from start to finish and that the host economizes by using the same receptors with different agonists. 
In support of this, a distinct profile of endogenous $\mathrm{LXA}_{4}$ and annexin-1 generation was found in the cellfree exudates of a mouse air-pouch model of resolving inflammation, with $\mathrm{LXA}_{4}$ peaking at 4 hours but higher annexin-1 levels detectable at 20 hours post-insult, occurring at the same time as reduced PMN influx ${ }^{124}$. Consistently, passive immunization of mice with neutralizing anti-annexin-1 sera did not exacerbate PMN recruitment but prolonged $\mathrm{it}^{125}$. In this study, several parameters of the acute inflammatory response were altered by blockade of endogenous annexin-1, including the profile of cytokine and proteolytic enzyme release. The recent generation of annexin-1null mice confirm these findings. Several markers of acute inflammation are exacerbated in these animals, including the oedema (vascular) response and PMN recruitment ${ }^{126}$. Annexin-1-null mice also have an altered susceptibility of some of these inflammatory responses to glucocorticoid treatment ${ }^{126}$. It is important that similar observations have also been produced in a model of chronic joint inflammation ${ }^{127}$, thereby highlighting potential therapeutic application of annexin-1 mimetics. So, the discovery that annexin- 1 and its antiinflammatory peptido-mimetics bind to ALX can open the way to the development of novel small-molecule entities based on annexin-1 (REF. 128), thereby, at least in part, retaining some of the anti-inflammatory properties of glucocorticoids that signal the resolution of ongoing inflammatory lesions.

\section{Current drugs that may trigger resolution}

To the author's knowledge, there are no drugs in the clinic that are purposefully based on the elicitation of proresolving pathways, with the exception of those drugs that target apoptosis ${ }^{93}$. There are, however, drugs in current usage that mediate their effects, at least in part, by triggering the synthesis of endogenous anti-inflammatory

\section{Box 4 | Examples of non-resolving inflammatory disease processes}

This box includes known drugs that mediate some anti-inflammatory effects through the induction of endogenous anti-inflammatory mediators. In doing so, they might control ongoing inflammation by triggering resolution, a possibility that requires further clarification. The shortness of this list reflects the scarcity of drugs developed on the basis of pro-resolution properties.

Non-resolving inflammatory disorders

- Arthritis

- Nephritis

- Asthma

- Bronchitis

- Chronic granulomatous disease

- Psoriasis

Drugs that might mediate resolution

- Methotrexate

- Sulphasalazine

- FK506

- Drugs designed for the regulation of apoptosis (see REF. 93 for a detailed description of the disease targets and mechanisms of action) mediators in a manner that might be related to proresolution. These include methotrexate, sulphasalazine and FK506, which are thought to exert their effects by increasing adenosine release ${ }^{129}$. Adenosine works through four $\mathrm{G}$-protein-coupled receptors that are designated $A_{1}, A_{2 A}, A_{2 B}$ and $A_{3}$, and generally signals through the cAMP pathway to dampen inflammation ${ }^{130}$. Methotrexate, for instance, is a widely used and highly effective drug for the treatment of rheumatoid arthritis and other inflammatory diseases. Data from in vitro studies have shown that methotrexate increases adenosine release from co-cultures of stimulated PMNs and umbilical-vein endothelial cells or stimulated PMNs and fibroblasts by inhi-bitingAICAR( 5 aminoimidazole-4-carboxamidoribonucleotide) transformylase, resulting in the accumulation of AICAR, which is the nucleoside precursor that has previously been shown to cause adenosine release from ischaemic cardiac tissue ${ }^{131}$. Moreover, in vivo studies showed that adenosine, working through the $\mathrm{A}_{2}$ receptors, mediates the anti-inflammatory effects of methotrexate in mice ${ }^{132}$, an observation that has been confirmed in adenosine$\mathrm{A}_{2 \mathrm{~A}}$ - and adenosine- $\mathrm{A}_{3}$-receptor-deficient mice ${ }^{133}$. Adenosine fits well with our theme of resolution as it not only prevents leukocyte trafficking but it might also switch off acute inflammation by downregulating macrophage activation ${ }^{134}$ and by favouring $\mathrm{T}_{\mathrm{H}} 2$ - versus $\mathrm{T}_{\mathrm{H}} 1$-cell development ${ }^{135}$. Therefore, adenosine or adenosine receptor occupancy on cells of the immune system presents a potential target for pro-resolving therapy, with the exception of asthma and chronic obstructive pulmonary disease in which there are continuously high endogenous levels of adenosine, which has been suggested to contribute to the chronic nature of the disease ${ }^{136}$. Similar considerations, although not yet supported by drugs in clinical use, could be put forward for another family of five G-protein-coupled receptors that signal through the cAMP - the melanocortin receptors ${ }^{137}$. There are many chronic inflammatory diseases (BOX 4) that could benefit from a treatment regimen that, somehow, leads to resolution of an ongoing inflammatory response. Drugs such as methotrexate, sulphasalazine and FK506, which trigger the synthesis of endogenous factors with established anti-inflammatory and possibly pro-resolving properties, provide support for the concept of activating pro-resolution pathways to treat chronic inflammation.

\section{Future directions}

Developing drugs based on endogenous mediators that are inherent to resolution might represent a new strategy in anti-inflammatory therapy. So far, a number of factors have been identified, including the LXs and the resolvins, which although are unstable with short half-lives in vivo, exert powerful alleviating effects when used in their native form or, particularly, as stable analogues to treat experimental inflammatory diseases. Therefore, the development of compliant mimetics based on their structure shows great promise for clinical usage. Indeed, efforts in LX research have identified that the LX receptor, in addition to binding some of 
the LX family of LOX/LOX interaction products, also binds other endogenous factors, including the glucocorticoid-inducible annexin-1 (REF. 122). This has consequences for understanding the nature of the endogenous control of resolving inflammation, showing how anti-inflammatory mediators of differing structure and metabolic origin can exert their antiinflammatory effects through the same receptor. On this theme, our ongoing challenge is to identify novel receptors, the activation of which is integral to resolving inflammation, thereby presenting alternative targets for drug development ${ }^{128}$. Other potential pro-resolving lipid mediators for drug targeting are $\mathrm{PGD}_{2}$ metabolites. We found a crucially important role for these eicosanoids in controlling the severity and progression of an experimental T-lymphocyte-mediated delayed-type hypersensitivity, indicating that stable analogues of these eicosanoids might prove beneficial in the management of certain immune-mediated diseases, such as rheumatoid arthritis or encephalomyelitis. However, as already mentioned, $\mathrm{PGD}_{2}$ metabolites seem to exacerbate allergic lung diseases, almost certainly indicating organ-specific pathways of inflammatory resolution. This is important for drug development for resolving inflammation as not all organs have the same pro-resolving machinery. A good example of this is in the kidney: a model of glomerulonephritis showed that only a small percentage of influxing PMNs are phagocytosed after undergoing apoptosis, with most being cleared from the inflamed glomeruli by returning to the circulation ${ }^{74}$. This indicates that although the end result is resolution, the cellular mechanisms that ultimately switch off acute inflammation might be organ specific.

Seminal work on the fate of inflammatory leukocytes has revealed that not only is apoptosis of PMNs and eosinophils crucial as a basic mechanism of cell disposal, but that the apoptotic cells themselves express on their surface a repertoire of signals, of which phosphatidylserine is well characterized ${ }^{138}$. These signals facilitate their phagocytosis, and hence clearance, by macrophages, while at the same time programming the phagocytosing macrophage into an anti-inflammatory or pro-resolution phenotype. Interestingly, rapid membrane translocation of annexin-1 in T cells entering into apoptosis also favours phagocytosis by macrophages and other cleaning cells ${ }^{139}$. It is therefore not surprising that injection of apoptotic PMNs or phosphatidylserine
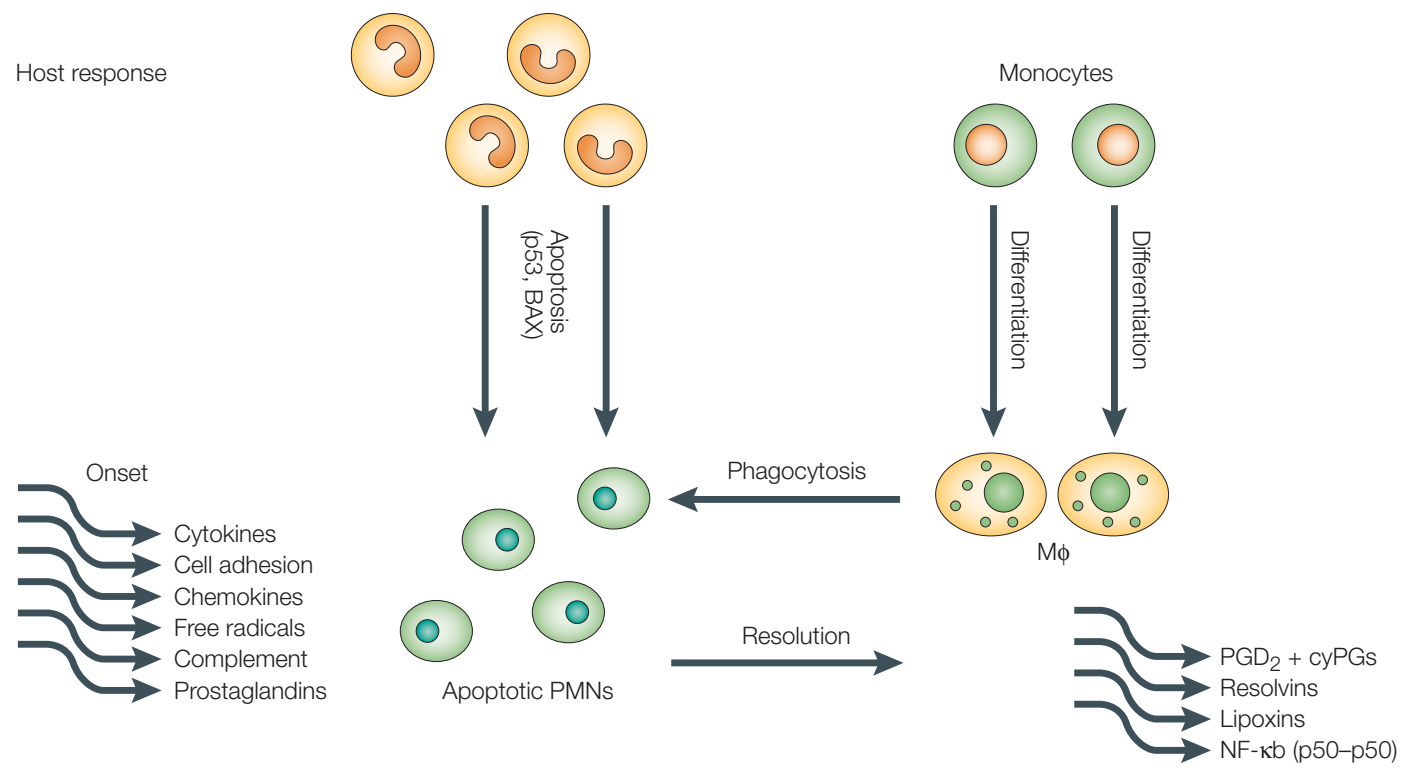

Time up to 72 hours

Figure 6 | A general schematic summarizing the mediators and mechanisms that drive and switch off acute innate inflammation. During the early phases of acute inflammation and under the control of endogenous cytokines, chemokines, cell-adhesion molecules and other pro-inflammatory stimuli, polymorphonuclear leukocytes (PMNs) or eosinophils (depending on the nature of the stimulus) migrate into the inflamed site and, along with oedema, begin the task of neutralizing the injurious agent. These leukocytes undergo apoptosis or programmed cell death, which, in vivo, can take from 24-48 hours for PMNs or much longer for eosinophils. From our studies, it seems that BAX and p53 have a role in PMN apoptosis during resolution. Within time (anything from 6-24 hours, depending again on the nature and 'quantity' of the stimulus), monocytes are recruited, which differentiate to larger, more granular macrophages. These macrophages, which are generally fewer in number than the PMN infiltrate, set about phagocytosing apoptotic PMNs or eosinophils. During this phase of active resolution, Reiter cells (macrophages containing, usually, 2-4 effete leukocytes) can be observed histologically. When the apoptotic leukocytes are cleared, macrophages must also be disposed of in order to prevent, for instance, granuloma tissue formation. The fate of macrophages is either local-cell apoptosis or lymphatic drainage. The events controlling leukocyte apoptosis, phagocytosis and macrophage clearance are not well understood, but it is known so far that the lipoxins, resolvins, annexin-1, $P G D_{2}$ (prostaglandin $\mathrm{D}_{2}$ ) metabolites and nuclear factor of $\mathrm{\kappa B}(\mathrm{NF}-\mathrm{\kappa B}$ ) subunits (p50-p50) are crucial in resolution. 
liposomes in a model of peritonitis accelerates resolution ${ }^{140}$ and a similar intervention inhibits onset of experimental arthritis ${ }^{141}$. This could provide the impetus to develop drugs that mimic the signals displayed by apoptosing cells and enhancing the capacity of infiltrating or resident macrophages to phagocytose, with the LXs and the glucocorticoids showing particular effect in this area. As well as soluble mediators, the NF- $\mathrm{KB}$ pathway has sprung some unexpected surprises namely, its role in pro-resolution through the preferential binding of the p50-p50 anti-inflammatory subunits. Understanding the signals that preferentially favour this subunit complex formation will help in the development of drugs that speed up resolution through the induction of apoptosis. A temporal profile of the events leading to resolution and mediators that control them, as we understand them today, is shown in FIG. 6 .

\section{Summary}

In conclusion, we believe that failure of acute inflammation to adequately resolve might contribute to the development of chronic inflammation and even autoimmunity. We therefore suggest developing drugs that mimic the actions of mediators that are essential for resolution to treat chronic inflammatory diseases, such as rheumatoid arthritis, asthma and encephalomyelitis, for example. Such therapeutics might be based on the mechanisms of action of cyPGs, lipoxins or lipoxin-receptor agonists, or on factors that trigger leukocyte apoptosis and stimulate macrophage phagocytosis of apoptotic cells. In doing so, it might be possible to 'trick' ongoing inflammation into resolution. Unfortunately, such therapeutics, with the exception of those that regulate leukocyte apoptosis ${ }^{93}$, are far from the clinic. This reflects the relative immaturity of this field of research. However, further investigation into the mediators and mechanisms that are central to resolution will bring us into a new era of inflammation research, which, if approached with creativity and persistence, might provide numerous benefits for those suffering from inflammationmediated diseases.
1. Florey, H. W. General Pathology (Lloyd-Luke Ltd, London, 1970).

Provides a fantastic historical perspective of inflammation research as well as detailed accounts of some of the classic experiments that have contributed to our current understanding of the inflammatory response.

2. Cotran, R. S., Kumar, V. \& Collins, T. (eds) in Robbins Pathologic Basis of Disease Vol. 6 50-88 (W. B. Saunders Company, Philadelphia, 1999).

3. Cotran, R. S., Kumar, V. \& Collins, T. (eds) in Robbins Pathologic Basis of Disease Vol. 6 89-112 (W. B Saunders and Company, Philadelphia, 1999).

4. Dumonde, D. C. \& Glynn, L. E. The production of arthritis in rabbits by an immunological reaction to fibrin. Br. J. Exp. Pathol. 43, 373 (1962).

5. Dumonde, D. C. \& Glynn, L. E. The reaction of guinea-pigs to autologous and heterologous fibrin implants. J. Pathol. Bacteriol. 90, 649-657 (1965).

6. Weissmann, G., Becher, G., Wiedermann, G. \& Bernheimer, A. W. Studies on lysozymes. VII. Acute and chronic arthritis produced by intra-articular injections of streptolysin 'S' in rabbits. Am. J. Pathol. 46, 129 (1965).

7. Willoughby, D. A. \& Ryan, G. B. Evidence for a possible endogenous antigen in chronic inflammation. J. Pathol. 101, 233-239 (1970).

8. Recommendations for the prevention and treatment of glucocorticoid-induced osteoporosis: 2001 update. American College of Rheumatology Ad Hoc Committee on Glucocoritcoid-Induced Osteoporosis. Arthritis Rheum. 44 1496-1503 (2001).

9. Beer, H. D., Fassler, R. \& Werner, S. Glucocorticoidregulated gene expression during cutaneous wound repair. Vitam. Horm. 59, 217-239 (2000).

10. Mukherjee, D. Selective cyclooxygenase-2 (COX-2) inhibitors and potential risk of cardiovascular events. Biochem. Pharmacol. 63, 817-821 (2002).

11. Antoni, C. \& Braun, J. Side effects of anti-TNF therapy: current knowledge. Clin. Exp. Rheumatol. 20, S152-S157 (2002).

12. Urade, Y. \& Hayaishi, O. Prostaglandin D synthase: structure and function. Vitam. Horm. 58, 89-120 (2000).

13. Straus, D. S. \& Glass, C. K. Cyclopentenone prostaglandins: new insights on biological activities and cellular targets. Med. Res. Rev. 21, 185-210 (2001).

This is a comprehensive review of cyclopentenone prostaglandins that covers their synthesis, structure and role in pathophysiology.

14. Jiang, C., Ting, A. T. \& Seed, B. PPAR-gamma agonists inhibit production of monocyte inflammatory cytokines. Nature 391, 82-86 (1998)

15. Ricote, M., Li, A. C., Willson, T. M., Kelly, C. J. \& Glass, C. K The peroxisome proliferator-activated receptor-gamma is a negative regulator of macrophage activation. Nature $\mathbf{3 9 1}$, 79-82 (1998).
References 14 and 15 report on the receptor-mediated actions of the cyclopentenone prostaglandins that lead to a suppression of inflammation.

16. Nosjean, O. \& Boutin, J. A. Natural ligands of PPARgamma: are prostaglandin $\mathrm{J}(2)$ derivatives really playing the part? Cell Signal. 14, 573-583 (2002).

17. Straus, D. S. et al. 15-deoxy-delta 12,14-prostaglandin J2 inhibits multiple steps in the NF-kappa B signaling pathway. Proc. Natl Acad. Sci. USA 97, 4844-4849 (2000).

18. Perez-Sala, D., Cernuda-Morollon, E. \& Canada, F. J. Molecular basis for the direct inhibition of AP-1 DNA binding by 15-deoxy-Delta 12,14-prostaglandin J2. J. Biol. Chem. 278, 51251-51260 (2003).

19. Chen, C. W., Chang, Y. H., Tsi, C. J. \& Lin, W. W. Inhibition of IFN-gamma-mediated inducible nitric oxide synthase induction by the peroxisome proliferator-activated receptor gamma agonist, 15-deoxy-delta 12 , 14-prostaglandin J2, involves inhibition of the upstream Janus kinase/STAT1 signaling pathway. J. Immunol. 171, 979-988 (2003)

20. Maggi, L. B. Jr et al. Anti-inflammatory actions of 15-deoxydelta 12,14-prostaglandin J2 and troglitazone: evidence for heat shock-dependent and-independent inhibition of cytokine-induced inducible nitric oxide synthase expression. Diabetes 49, 346-355 (2000).

21. Petrova, T. V., Akama, K. T. \& Van Eldik, L. J. Cyclopentenone prostaglandins suppress activation of microglia: down-regulation of inducible nitric-oxide synthase by 15-deoxy-Delta12,14-prostaglandin J2. Proc. Natl Acad. Sci. USA 96, 4668-4673 (1999).

22. Bernardo, A., Levi, G. \& Minghetti, L. Role of the peroxisome proliferator-activated receptor-gamma (PPAR-gamma) and its natural ligand 15-deoxy-Delta12, 14-prostaglandin J2 in the regulation of microglial functions. Eur. J. Neurosci. 12, 2215-2223 (2000).

23. Gosset, P. et al. Prostaglandin D2 affects the maturation of human monocyte-derived dendritic cells: consequence on the polarization of naive Th cells. J. Immunol. 170, 494349-494352 (2003).

24. Jackson, S. M. et al. Peroxisome proliferator-activated receptor activators target human endothelial cells to inhibit leukocyte-endothelial cell interaction. Arterioscler. Thromb. Vasc. Biol. 19, 2094-2104 (1999).

25. Pasceri, V., Wu, H. D., Willerson, J. T. \& Yeh, E. T. Modulation of vascular inflammation in vitro and in vivo by peroxisome proliferator-activated receptor-gamma activators. Circulation 101, 235-238 (2000).

26. Zhang, X., Wang, J. M., Gong, W. H., Mukaida, N. \& Young, $H$. A. Differential regulation of chemokine gene expression by 15-deoxy-delta 12,14 prostaglandin $\mathrm{J} 2$. J. Immunol. 166, 7104-7111 (2001).

27. Zernecke, A., Erl, W., Fraemohs, L., Lietz, M. \& Weber, C. Suppression of endothelial adhesion molecule up-regulation with cyclopentenone prostaglandins is dissociated from
IkappaB-alpha kinase inhibition and cell death induction. FASEB J. 17, 1099-1101 (2003).

28. Gilroy, D. W., Tomlinson, A. \& Willoughby, D. A. Differentia effects of inhibitors of cyclooxygenase (cyclooxygenase 1 and cyclooxygenase 2) in acute inflammation. Eur. J. Pharmacol. 355, 211-217 (1998).

29. Gilroy, D. W. et al. Inducible cyclooxygenase may have antiinflammatory properties. Nature Med. 5, 698-701 (1999). This paper originally described the synthesis of antiinflammatory eicosanoids during acute inflammatory resolution, thereby highlighting that the host actively manufactures soluble mediators to switch off acute inflammation and limit tissue damage.

30. Gilroy, D. W., Newson, J., Sawmynaden, P., Willoughby, D. A \& Croxtall, J. D. A novel role for phospholipase A2 isoforms in the checkpoint control of acute inflammation. FASEB J. 18, 489-498 (2004)

31. Gilroy, D. W. et al. Inducible cyclooxygenase-derived 15-deoxy(Delta)12-14PGJ2 brings about acute inflammatory resolution in rat pleurisy by inducing neutrophil and macrophage apoptosis. FASEB J. 17, 2269-2271 (2003)

32. Ward, C. et al. Prostaglandin D2 and its metabolites induce caspase-dependent granulocyte apoptosis that is mediated via inhibition of I kappa B alpha degradation using a peroxisome proliferator-activated receptor-gamma-independent mechanism. J. Immunol. 168, 6232-6243 (2002).

33. Castrillo, $\mathrm{A}$. et al. Potentiation of protein kinase $\mathrm{C}$ zeta activity by 15 -deoxy-delta(12,14)-prostaglandin J(2) induces an imbalance between mitogen-activated protein kinases and NF-kappaB that promotes apoptosis in macrophages. Mol. Cell Biol. 23, 1196-1208 (2003).

34. Li, L. et al. 15-deoxy-delta 12,14-prostaglandin J2 induces apoptosis of human hepatic myofibroblasts. A pathway involving oxidative stress independently of peroxisomeproliferator-activated receptors. J. Biol. Chem. 276, 38152-38158 (2001)

35. Reference deleted in proof

36. Setoguchi, K. et al. Peroxisome proliferator-activated receptor-gamma haploinsufficiency enhances B cell proliferative responses and exacerbates experimentally induced arthritis. J. Clin. Invest. 108, 1667-1675 (2001).

37. Ando, M. et al. Retrovirally introduced prostaglandin D2 synthase suppresses lung injury induced by bleomycin. Am. J. Respir. Cell. Mol. Biol. 28, 582-591 (2003).

38. Cuzzocrea, S. et al. The cyclopentenone prostaglandin 15-deoxy-delta(12,14)-PGJ ${ }_{2}$ attenuates the development of colon injury caused by dinitrobenzene sulphonic acid in the rat. Br. J. Pharmacol. 138, 678-688 (2003).

39. Chatterjee, P. K. et al. The cyclopentenone prostaglandin 15-deoxy-Delta(12,14)-prostaglandin J(2) ameliorates ischemic acute renal failure. Cardiovasc. Res. 61, 630-643 (2004).

40. Kawahito, Y. et al. 15-deoxy-delta(12,14)-PGJ(2) induces synoviocyte apoptosis and suppresses adjuvantinduced arthritis in rats. J. Clin. Invest. 106, 189-197 (2000). 
41. Diab, A. et al. Peroxisome proliferator-activated receptorgamma agonist 15-deoxy-delta(12,14)-prostaglandin J(2) ameliorates experimental autoimmune encephalomyelitis. J. Immunol. 168, 2508-2515 (2002).

42. Matsuoka, T. et al. Prostaglandin D2 as a mediator of allergic asthma. Science 287, 2013-2017 (2000).

43. Honda, K. et al. Prostaglandin D2 reinforces $T_{H} 2$ type inflammatory responses of airways to low-dose antigen through bronchial expression of macrophage-derived chemokine. J. Exp. Med. 198, 533-543 (2003).

44. Lee, T. S., Tsai, H. L. \& Chau, L. Y. Induction of heme oxygenase-1 expression in murine macrophages is essential for the anti-inflammatory effect of low dose 15-deoxy-delta 12,14-prostaglandin J2. J. Biol. Chem. 278, 19325-19330 (2003).

45. Ryter, S. W., Otterbein, L. E., Morse, D. \& Choi, A. M. Heme oxygenase/carbon monoxide signaling pathways: regulation and functional significance. Mol. Cell. Biochem. 234-235 249-263 (2002).

46. Willis, D. M. A., Frederick, R. \& Willoughby, D. A. Heme oxygenase: a novel target for the modulation of the inflammatory response Nature Med 2 87-90 (1996).

47. Graca-Souza, A. V., Arruda, M. A., de Freitas, M. S., Barja-Fidalgo, C. \& Oliveira, P. L. Neutrophil activation by heme: implications for inflammatory processes. Blood $\mathbf{9 9}$, 4160-4165 (2002)

48. Alcaraz, M. J., Fernandez, P. \& Guillen, M. I. Antiinflammatory actions of the heme oxygenase-1 pathway. Curr. Pharm. Des. 9, 2541-2551 (2003).

49. Sato, K. et al. Carbon monoxide generated by heme oxygenase-1 suppresses the rejection of mouse-to-rat cardiac transplants. J. Immunol. 166, 4185-4194 (2001).

50. Hancock, W. W., Buelow, R., Sayegh, M. H. \& Turka, L. A. Antibody-induced transplant arteriosclerosis is prevented by graft expression of anti-oxidant and anti-apoptotic genes. Nature Med. 4, 1392-1396 (1998)

51. Woo, J., lyer, S., Mori, N. \& Buelow, R. Alleviation of graft-versus-host disease after conditioning with cobalt-protoporphyrin, an inducer of heme oxygenase- 1 . Transplantation 69, 623-633 (2000).

52. Levy, B. D., Clish, C. B., Schmidt, B., Gronert, K. \& Serhan, C. N. Lipid mediator class switching during acute inflammation: signals in resolution. Nature Immunol. 2, 612-619 (2001).

In addition to reference 25 , this paper reinforces the concept of lipid mediator class switching from proinflammatory at the onset of acute inflammation to pro-resolving at resolution.

53. Papayianni, A., Serhan, C. N. \& Brady, H. R. Lipoxin A4 and B4 inhibit leukotriene-stimulated interactions of human neutrophils and endothelial cells. J. Immunol. 156 2264-2272 (1996).

54. Serhan, C. N., Takano, T., Clish, C. B., Gronert, K. \& Petasis, N. Aspirin-triggered 15-epi-lipoxin A4 and nove lipoxin B4 stable analogs inhibit neutrophil-mediated changes in vascular permeability. Adv. Exp. Med. Biol. 469 287-293 (1999).

55. Maddox, J. F. \& Serhan, C. N. Lipoxin A4 and B4 are potent stimuli for human monocyte migration and adhesion: selective inactivation by dehydrogenation and reduction. J. Exp. Med. 183, 137-146 (1996)

56. Maddox, J. F. et al. Lipoxin A4 stable analogs are potent mimetics that stimulate human monocytes and THP-1 cells via a G-protein-linked lipoxin A4 receptor. J. Biol. Chem. 272, 6972-6978 (1997).

57. Jozsef, L., Zouki, C., Petasis, N. A., Serhan, C. N. \& Filep, J. G. Lipoxin A4 and aspirin-triggered 15-epi-lipoxin A4 inhibit peroxynitrite formation, NF-kappa B and AP-1 activation, and IL-8 gene expression in human leukocytes. Proc. Natl Acad. Sci. USA 99, 13266-13271 (2002).

58. Bandeira-Melo, C. et al. Cyclooxygenase-2-derived prostaglandin E2 and lipoxin A4 accelerate resolution of allergic edema in Angiostrongylus costaricensis-infected rats: relationship with concurrent eosinophilia. J. Immunol. 164, 1029-1036 (2000)

59. Godson, C. et al. Cutting edge: lipoxins rapidly stimulate nonphlogistic phagocytosis of apoptotic neutrophils by monocyte-derived macrophages. J. Immunol. 164, 1663-1667 (2000)

60. Mitchell, S. et al. Lipoxins, aspirin-triggered epi-lipoxins, lipoxin stable analogues, and the resolution of inflammation: stimulation of macrophage phagocytosis of apoptotic neutrophils in vivo. J. Am. Soc. Nephrol. 13, 2497-2507 (2002)

61. Brink, C. et al. International Union of Pharmacology XXXVII. Nomenclature for leukotriene and lipoxin receptors. Pharmacol. Rev. 55, 195-227 (2003).
62. Bandeira-Melo, C. et al. Cutting edge: lipoxin $(L X) A 4$ and aspirin-triggered 15-epi-LXA4 block allergen-induced eosinophil trafficking. J. Immunol. 164, 2267-2271 (2000).

63. Serhan, C. N. et al. Novel functional sets of lipid-derived mediators with antiinflammatory actions generated from omega-3 fatty acids via cyclooxygenase 2-nonsteroidal antiinflammatory drugs and transcellular processing J. Exp. Med. 192, 1197-1204 (2000).

64. Serhan, C. N. et al. Resolvins: a family of bioactive products of omega- 3 fatty acid transformation circuits initiated by aspirin treatment that counter proinflammation signals. J. Exp. Med. 196, 1025-1037 (2002).

References 63 and 64 report on the role of aspirintriggered lipid mediator metabolites of polyunsaturated fatty acids and their spontaneous synthesis during the resolving phase of acute inflammation.

65. Hong, S., Gronert, K., Devchand, P. R., Moussignac, R. L. \& Serhan, C. N. Novel docosatrienes and 17S-resolvins generated from docosahexaenoic acid in murine brain, human blood and glial cells. Autacoids in anti-inflammation. J. Biol. Chem. 278, 14677-14687 (2003).

66. Brezinski, D. A., Nesto, R. W. \& Serhan, C. N. Angioplasty triggers intracoronary leukotrienes and lipoxin A4. Impact of aspirin therapy. Circulation 86, 56-63 (1992).

67. Van Dyke, T. E. \& Serhan, C. N. Resolution of inflammation: a new paradigm for the pathogenesis of periodontal diseases. J. Dent. Res. 82, 82-90 (2003).

68. Claria, J. et al. Altered biosynthesis of leukotrienes and lipoxins and host defense disorders in patients with cirrhosis and ascites. Gastroenterology 115, 147-156 (1998).

69. Levy, B. D. et al. Multi-pronged inhibition of airway hyperresponsiveness and inflammation by lipoxin $\mathrm{A}(4)$. Nature Med. 8, 1018-1023 (2002).

70. Munger, K. A. et al. Transfection of rat kidney with human 15-lipoxygenase suppresses inflammation and preserves function in experimental glomerulonephritis. Proc. Natl Acad. Sci. USA 96, 13375-13380 (1999).

71. Leonard, M. O. et al. 15-Epi-16-(para-fluorophenoxy)-lipoxin A(4)-methyl ester, a synthetic analogue of 15-epi-lipoxin A(4), is protective in experimental ischemic acute renal failure. J. Am. Soc. Nephrol. 13, 1657-1662 (2002).

72. Schottelius, A. J. et al. An aspirin-triggered lipoxin A4 stable analog displays a unique topical anti-inflammatory profile. J. Immunol. 169, 7063-7070 (2002).

73. Souza, M. H., de Lima, O. M., Zamuner, S. R., Fiorucci, S. \& Wallace, J. L. Gastritis increases resistance to aspirininduced mucosal injury via COX-2-mediated lipoxin synthesis. Am. J. Physiol. Gastrointest. Liver Physiol. 285 G54-G61 (2003).

74. Hughes, J. et al. Neutrophil fate in experimental glomerular capillary injury in the rat. Emigration exceeds in situ clearance by apoptosis. Am. J. Pathol. 150, 223-234 (1997).

75. Martin, C. et al. Chemokines acting via CXCR2 and CXCR4 control the release of neutrophils from the bone marrow and their return following senescence. Immunity 19, 583-593 (2003).

76. Bellingan, G. J., Caldwell, H., Howie, S. E., Dransfield, I. \& Haslett, C. In vivo fate of the inflammatory macrophage during the resolution of inflammation: inflammatory macrophages do not die locally, but emigrate to the draining lymph nodes. J. Immunol. 157, 2577-2585 (1996).

77. Bellingan, G. J. et al. Adhesion molecule-dependent mechanisms regulate the rate of macrophage clearance during the resolution of peritoneal inflammation. J. Exp. Med. 196, 1515-1521 (2002)

References 76 and 77 show comprehensively that in resolving peritonitis, the fate of macrophage clearance is through lymphatic drainage.

78. Savill, J. \& Fadok, V. Corpse clearance defines the meaning of cell death. Nature 407, 784-788 (2000).

A concise review highlighting the concept of apoptosis and phagocytosis and their relevance to inflammatory disease processes.

79. Nicholson, D. W. From bench to clinic with apoptosis-based therapeutic agents. Nature 407,810-816 (2000).

80. Brunner, T. \& Mueller, C. Apoptosis in disease: about shortage and excess. Essays Biochem. 39, 119-130 (2003).

81. Fadok, V. A., Bratton, D. L. \& Henson, P. M. Phagocyte receptors for apoptotic cells: recognition, uptake, and consequences. J. Clin. Invest. 108, 957-962 (2001).

82. Savill, J., Dransfield, I., Gregory, C. \& Haslett, C. A blast from the past: clearance of apoptotic cells regulates immun responses. Nature Rev. Immunol. 2, 965-975 (2002).

83. Ward, C., Dransfield, I., Chilvers, E. R., Haslett, C. \& Rossi, A. Pharmacological manipulation of granulocyte apoptosis: potential therapeutic targets. Trends Pharmacol. Sci. 20 503-509 (1999).
84. Giles, K. M., Hart, S. P., Haslett, C., Rossi, A. G. \& Dransfield, I. An appetite for apoptotic cells? Controversies and challenges. Br. J. Haematol. 109, 1-12 (2000).

85. Rossi, A. G. et al. Regulation of macrophage phagocytosis of apoptotic cells by cAMP. J. Immunol. 160, 3562-3568 (1998).

86. Liu, Y. et al. Glucocorticoids promote nonphlogistic phagocytosis of apoptotic leukocytes. J. Immunol. 162, 3639-3646 (1999).

87. Giles, K. M. et al. Glucocorticoid augmentation of macrophage capacity for phagocytosis of apoptotic cells is associated with reduced p130Cas expression, loss of paxillin/pyk2 phosphorylation, and high levels of active Rac. J. Immunol. 167, 976-986 (2001).

88. Ren, Y. \& Savill, J. Proinflammatory cytokines potentiate thrombospondin-mediated phagocytosis of neutrophils undergoing apoptosis. J. Immunol. 154, 2366-2374 (1995).

89. McCutcheon, J. C. et al. Regulation of macrophage phagocytosis of apoptotic neutrophils by adhesion to fibronectin. J. Leukoc. Biol. 64, 600-607 (1998).

90. Hart, S. P., Dougherty, G. J., Haslett, C. \& Dransfield, L. CD44 regulates phagocytosis of apoptotic neutrophil granulocytes, but not apoptotic lymphocytes, by human macrophages. J. Immunol. 159, 919-925 (1997).

91. Teder, P. et al. Resolution of lung inflammation by CD44. Science 296, 155-158 (2002).

92. Woolley, K. L. et al. Eosinophil apoptosis and the resolution of airway inflammation in asthma. Am. J. Respir. Crit. Care Med. 154, 237-243 (1996).

93. Murphy, F. J., Seery, L. T. \& Hayes, I. Therapeutic approaches to the modulation of apoptosis. Essays Biochem. 39, 131-153 (2003).

94. Degterev, A., Boyce, M. \& Yuan, J. A decade of caspases. Oncogene 22, 8543-8567 (2003).

95. Earnshaw, W. C., Martins, L. M. \& Kaufmann, S. H. Mammalian caspases: structure, activation, substrates, and functions during apoptosis. Annu. Rev. Biochem. 68, 383-424 (1999).

96. Graczyk, P. P. Caspase inhibitors as anti-inflammatory and antiapoptotic agents. Prog. Med. Chem. 39, 1-72 (2002)

97. Iwata, A., Harlan, J. M., Vedder, N. B. \& Winn, R. K. The caspase inhibitor $z-V A D$ is more effective than CD18 adhesion blockade in reducing muscle ischemia-reperfusion injury: implication for clinical trials. Blood 100, 2077-2080 (2002).

98. Natori, S., Higuchi, H., Contreras, P. \& Gores, G. J. The caspase inhibitor IDN-6556 prevents caspase activation and apoptosis in sinusoidal endothelial cells during liver preservation injury. Liver Transpl. 9, 278-284 (2003).

99. Hoglen, N. C. et al. Characterization of IDN-6556: a livertargeted caspase inhibitor. J. Pharmacol. Exp. Ther. 23 Jan 2004 [epub ahead of print]

100. Valentino, K. L., Gutierrez, M., Sanchez, R., Winship, M. J. \& Shapiro, D. A. First clinical trial of a novel caspase inhibitor: anti-apoptotic caspase inhibitor, IDN-6556, improves liver enzymes. Int. J. Clin. Pharmacol. Ther. 41, 441-449 (2003).

101. Karin, M. New twists in gene regulation by glucocorticoid receptor: is DNA binding dispensable? Cell 93, 487-490 (1998)

102. Ghosh, S., May, M. J. \& Kopp, E. B. NF-kappa B and Re proteins: evolutionarily conserved mediators of immune responses. Annu. Rev. Immunol. 16, 225-260 (1998).

103. Khoshnan, A. et al. The NF-kappa B cascade is important in $\mathrm{Bcl}-\mathrm{XL}$ expression and for the anti-apoptotic effects of the CD28 receptor in primary human CD4+ lymphocytes. J. Immunol. 165, 1743-1754 (2000).

104. Ward, C. et al. NF-kappaB activation is a critical regulator of human granulocyte apoptosis in vitro. J. Biol. Chem. $\mathbf{2 7 4}$ 4309-4318 (1999).

105. Lawrence, T., Gilroy, D. W., Colville-Nash, P. R. \& Willoughby, D. A. Possible new role for NF-kappaB in the resolution of inflammation. Nature Med. 7, 1291-1297 (2001). Shows an important role for NF-KB in the resolution of acute inflammation that underpins a novel protective role for this otherwise pro-inflammatory factor.

106. Ishikawa, H. et al. Chronic inflammation and susceptibility to bacterial infections in mice lacking the polypeptide (p)105 precursor (NF-kappaB1) but expressing p50. J. Exp. Med. 187, 985-996 (1998)

107. Bohuslav, J. et al. Regulation of an essential innate immune response by the p50 subunit of NF-kappaB. J. Clin. Invest. 102, 1645-1652 (1998).

108. Chen, L. W. et al. The two faces of IKK and NF-kappaB inhibition: prevention of systemic inflammation but increased local injury following intestinal ischemia-reperfusion. Nature Med. 9, 575-581 (2003).

109. Munck, A., Guyre, P. M. \& Holbrook, N. J. Physiological functions of glucocorticoids in stress and their relation to pharmacological actions. Endocr. Rev. 5, 25-44 (1984). 
110. Flower, R. J., Parente, L., Persico, P. \& Salmon, J. A A comparison of the acute inflammatory response in adrenalectomised and sham-operated rats. Br. J. Pharmacol. 87, 57-62 (1986).

111. Perretti, M., Becherucci, C., Scapigliati, G. \& Parente, L. The effect of adrenalectomy on interleukin-1 release in vitro and in vivo. Br. J. Pharmacol. 98, 1137-1142 (1989).

112. Adcock, I. M. Molecular mechanisms of glucocorticosteroid actions. Pulm. Pharmacol. Ther. 13, 115-126 (2000).

113. Auphan, N., DiDonato, J. A., Rosette, C., Helmberg, A. \& Karin, M. Immunosuppression by glucocorticoids: inhibition of NF-kappa B activity through induction of I kappa B synthesis. Science 270, 286-290 (1995).

114. Buttgereit, F., Burmester, G. R. \& Brand, M. D. Bioenergetics of immune functions: fundamental and therapeutic aspects. Immunol. Today 21, 192-199 (2000).

115. Nissen, R. M. \& Yamamoto, K. R. The glucocorticoid receptor inhibits NFkappaB by interfering with serine-2 phosphorylation of the RNA polymerase II carboxy-terminal domain. Genes Dev. 14, 2314-2329 (2000).

116. Flower, R. J. Eleventh Gaddum memorial lecture. Lipocortin and the mechanism of action of the glucocorticoids. Br. J. Pharmacol. 94, 987-1015 (1988).

117. Croxtall, J. D. \& Flower, R. J. Lipocortin 1 mediates dexamethasone-induced growth arrest of the A549 lung adenocarcinoma cell line. Proc. Natl Acad. Sci. USA 89, 3571-3575 (1992)

118. De Caterina, R. et al. Macrophage-specific eicosanoid synthesis inhibition and lipocortin-1 induction by glucocorticoids. J. Appl. Physiol. 75, 2368-2375 (1993).

119. Mancuso, F., Flower, R. J. \& Perretti, M. Leukocyte transmigration, but not rolling or adhesion, is selectively inhibited by dexamethasone in the hamster post-capillary venule. Involvement of endogenous lipocortin 1. J. Immunol. 155, 377-386 (1995)

120. Perretti, M., Ahluwalia, A., Harris, J. G., Goulding, N. J. \& Flower, R. J. Lipocortin-1 fragments inhibit neutrophil accumulation and neutrophil-dependent edema in the mouse. A qualitative comparison with an anti-CD11b monoclonal antibody. J. Immunol. 151, 4306-4314 (1993).

121. Gerke, V. \& Moss, S. E. Annexins: from structure to function. Physiol. Rev. 82, 331-371 (2002).

122. Perretti, M. et al. Endogenous lipid-and peptide-derived anti-inflammatory pathways generated with glucocorticoid and aspirin treatment activate the lipoxin A4 receptor. Nature Med. 8, 1296-1302 (2002). Demonstrates, for the first time, the biochemical and functional link between endogenous and exogenous annexin-1 and ALX. Experiments of binding, immunoprecipitation and in vivo analyses of PMN recruitment support this novel idea.

123. Le, Y., Murphy, P. M. \& Wang, J. M. Formyl-peptide receptors revisited. Trends Immunol. 23, 541-548 (2002).

124. Perretti, M. \& Gavins, F. N. Annexin 1: an endogenous antiinflammatory protein. News Physiol. Sci. 18, 60-64 (2003).

125. Perretti, M. et al. Acute inflammatory response in the mouse: exacerbation by immunoneutralization of lipocortin $1 . \mathrm{Br} . \mathrm{J}$. Pharmacol. 117, 1145-1154 (1996).

126. Hannon, R. et al. Aberrant inflammation and resistance to glucocorticoids in annexin 1-/- mouse. FASEB J. 17, 253-255 (2003).
127. Yang, Y. H. et al. Modulation of inflammation and response to dexamethasone by Annexin 1 in antigen-induced arthritis. Arthritis Rheum. 50, 976-984 (2004).

References 126 and 127 were the first studies with the newly generated annexin-1-null mice to confirm the crucial, not redundant, role that this anti-inflammatory protein plays in prolonging the acute inflammatory response as well as in exacerbating joint inflammation in a model of arthritis.

128. Perretti, M. The annexin 1 receptor(s): is the plot unravelling? Trends Pharmacol. Sci. 24, 574-579 (2003). A concise review highlighting the opportunities that derive from the identification of the molecular targets that are responsible for annexin-1 actions.

129. Hasko, G. \& Cronstein, B. N. Adenosine: an endogenous regulator of innate immunity. Trends Immunol. 25, 33-39 (2004).

130. Sitkovsky, M. V. Use of the $A(2 A)$ adenosine receptor as a physiological immunosuppressor and to engineer inflammation in vivo. Biochem. Pharmacol. 65, 493-501 (2003).

131. Cronstein, B. N., Eberle, M. A., Gruber, H. E. \& Levin, R. I. Methotrexate inhibits neutrophil function by stimulating adenosine release from connective tissue cells. Proc. Nat Acad. Sci. USA 88, 2441-2445 (1991).

132. Cronstein, B. N., Naime, D. \& Ostad, E. The antiinflammatory mechanism of methotrexate. Increased adenosine release at inflamed sites diminishes leukocyte accumulation in an in vivo model of inflammation. J. Clin. Invest. 92, 2675-2682 (1993).

133. Montesinos, M. C. et al. Adenosine A2A or A3 receptors are required for inhibition of inflammation by methotrexate and its analog MX-68. Arthritis Rheum. 48, 240-247 (2003).

134. Xaus, J. et al. IFN-gamma up-regulates the A2B adenosine receptor expression in macrophages: a mechanism of macrophage deactivation. J. Immunol. 162, 3607-3614 (1999).

135. Hasko, G., Deitch, E. A., Szabo, C., Nemeth, Z. H. \& Vizi, E. S. Adenosine: a potential mediator of immunosuppression in multiple organ failure. Curr. Opin. Pharmacol. 2, 440-444 (2002).

136. Blackburn, M. R. Too much of a good thing: adenosine overload in adenosine-deaminase-deficient mice. Trends Pharmacol. Sci. 24, 66-70 (2003).

137. Catania, A., Gatti, S., Colombo, G. \& Lipton, J.M. Targeting melanocortin receptors as a novel strategy to control inflammation. Pharmacol. Rev. 56, 1-29 (2004).

138. Fadok, V. A., Bratton, D. L., Frasch, S. C., Warner, M. L. \& Henson, P. M. The role of phosphatidylserine in recognition of apoptotic cells by phagocytes. Cell Death Differ. $\mathbf{5}$ 551-562 (1998).

139. Arur, S. et al. Annexin I is an endogenous ligand that mediates apoptotic cell engulfment. Dev. Cell 4, 587-598 (2003).

140. Huynh, M. L., Fadok, V. A. \& Henson, P. M. Phosphatidylserine-dependent ingestion of apoptotic cells promotes TGF-beta1 secretion and the resolution of inflammation. J. Clin. Invest. 109, 41-50 (2002).

141. Blom, A. B., van Lent, P. L., Holthuysen, A. E. \& van den Berg, W. B. Skewed balances in regulation of stimulating and inhibitory FC gamma receptors on macrophages of CIA sensitive mice. Inflamm. Res. 50 (Suppl. 3), S155 (2001).
142. Edenius, C., Haeggstrom, J \& Lindgren, J. A. Transcellular conversion of endogenous arachidonic acid to lipoxins in mixed human platelet-granulocyte suspensions. Biochem. Biophys. Res. Commun. 157, 801-807 (1988).

143. Fiore, S. \& Serhan, C. N. Formation of lipoxins and leukotrienes during receptor-mediated interactions of human platelets and recombinant human granulocyte/macrophage colony-stimulating factor-primed neutrophils. J. Exp. Med. 172, 1451-1457 (1990).

144. Serhan, C. N., Hamberg, M. \& Samuelsson, B. Lipoxins: novel series of biologically active compounds formed from arachidonic acid in human leukocytes. Proc. Natl Acad. Sci. USA 81, 5335-5339 (1984).

145. Claria, J. \& Serhan, C. N. Aspirin triggers previously undescribed bioactive eicosanoids by human endothelia cell-leukocyte interactions. Proc. Natl Acad. Sci. USA 92 9475-9479 (1995).

146. McLoughlin, R. M. et al. Interplay between IFN-gamma and IL-6 signaling governs neutrophil trafficking and apoptosis during acute inflammation. J. Clin. Invest. 112, 598-607 (2003).

147. Hurst, S. M. et al. II-6 and its soluble receptor orchestrate a temporal switch in the pattern of leukocyte recruitment seen during acute inflammation. Immunity 14, 705-714 (2001).

148. Rossi, A. et al. Anti-inflammatory cyclopentenone prostaglandins are direct inhibitors of lkappaB kinase. Nature 403, 103-108 (2000).

149. Castrillo, A., Diaz-Guerra, M. J., Hortelano, S., Martin-Sanz, P. \& Bosca, L. Inhibition of IkappaB kinase and IkappaB phosphorylation by 15-deoxy-delta(12,14)-prostaglandin $\mathrm{J}(2)$ in activated murine macrophages. Mol. Cell. Biol. 20 1692-1698 (2000).

150. Cernuda-Morollon, E., Pineda-Molina, E., Canada, F. J. \& Perez-Sala, D. 15-Deoxy-delta 12,14-prostaglandin J2 inhibition of NF-kappaB-DNA binding through covalent modification of the p50 subunit. J. Biol. Chem. 276 35530-35536 (2001).

References 148-150 show that the cyclopentenone prostaglandins have potent inhibitory signalling effects by directly binding to and altering NF-KB activation in addition to their modes of action discussed in references 14 and 15.

151. Bell-Parikh, L. C. et al. Biosynthesis of 15-deoxy delta12,14-PGJ2 and the ligation of PPARgamma. J. Clin. Invest. 112, 945-955 (2003).

Competing interests statement

The authors declare that they have no competing financial interests.

\section{(4) Online links}

\section{DATABASES}

The following terms in this article are linked online to:

LocusLink: http://www.ncbi.nlm.nih.gov/LocusLink/ ALXR | annexin-1 | BAX | BCL2 | BCL3 | CD40L | CD44 | COX2 |

FASR | FOS | FPRL2 | IL-1 | | IL-12 | JUN | NF-kB | p50 | p53 | PPAR $\gamma$ |RELA | TNF- $\alpha$

OMIM: http://www.ncbi.nlm.nih.gov/LocusLink/LocRpt.cgi?l=3553 Alzheimer's disease | asthma | atopic dermatitis |

Huntingdon's disease | multiple sclerosis | Parkinson's disease rheumatoid arthritis

Access to this links box is available online. 